\title{
Future Changes in the South Asian Summer Monsoon: An Analysis of the CMIP3 Multimodel Projections
}

\author{
Fangxing Fan,* Michael E. Mann, Sukyoung Lee, and Jenni L. Evans \\ Department of Meteorology, and Earth and Environmental Systems Institute, The Pennsylvania State University, \\ University Park, Pennsylvania
}

(Manuscript received 3 March 2011, in final form 29 November 2011)

\begin{abstract}
The projected future behavior of the South Asian summer monsoon (SASM) is analyzed for the 720-ppm stabilization experiments [Special Report on Emissions Scenarios (SRES) A1B] of phase 3 of the Coupled Model Intercomparison Project (CMIP3) simulations. The multimodel ensemble collectively exhibits a clear tendency for weakening SASM circulation and strengthening SASM precipitation during the twenty-first century. These tendencies are consistent, moreover, among multiple realizations for the same model where available.

An annual correlation analysis and thermodynamic energy budget analysis are used to investigate the changes in the monsoon circulation, precipitation (latent heating), and dry static stability across time scales of variation. The strength of the SASM circulation is interpreted in terms of two competing factors: convective latent heating and dry static stability. It is found that on interannual time scales the latent heating wins out over the dry static stability to dominate the interannual fluctuations of the monsoonal circulation. However, the long-term trends in the SASM circulation are governed by the competing effects of the convective latent heating term and the adiabatic term to modify dry static stability in the thermodynamic energy budget.
\end{abstract}

\section{Introduction}

In part because of its socioeconomic relevance, the possible future response of the South Asian summer monsoon (SASM) to anthropogenic forcing has been the subject of a number of previous climate-modeling studies. Yet there is no clear consensus among past studies regarding the projected changes in SASM circulation and SASM-related precipitation.

Different dynamical measures used to define the SASM circulation may have different trends in response to global warming. Dynamical monsoon indices based on vertical shear of the zonal wind (Webster and Yang index; Webster and Yang 1992) and horizontal shear of the zonal wind (the Indian monsoon index; Wang et al.

\footnotetext{
* Current affiliation: Department of Geosciences, University of Massachusetts-Amherst, Amherst, Massachusetts.

Corresponding author address: Fangxing Fan, Department of Geosciences, University of Massachusetts-Amherst, Amherst, MA 01003

E-mail: fangxing@geo.umass.edu
}

2001) indicate a weakening of the large-scale monsoon circulation, whereas the long-term trend of an index based instead on vertical shear of the meridional wind (Monsoon Hadley index; Goswami et al. 1999) in response to global warming is model dependent (Douville et al. 2000; Ashrit et al. 2003; Krishna Kumar et al. 2011). Douville et al. (2000) found a large spread among four atmospheric GCMs in the response of Indian summer monsoon precipitation to greenhouse gas forcing. Most studies, however, suggest increased SASM precipitation in response to greenhouse gas forcing (Meehl and Washington 1993; Bhaskaran et al. 1995; Kitoh et al. 1997; Hu et al. 2000; Lal et al. 2000; Meehl and Arblaster 2003; May 2002, 2004; Dairaku and Emori 2006; Meehl et al. 2007). Even when the additional, mitigating impact of sulfate aerosol forcing is accounted for, analyses of two transient climate change simulations by Ashrit et al. (2003) support an increase in monsoonal precipitation over India in response to anthropogenic climate forcing.

While some earlier studies attributed the projected increase in monsoon precipitation to the strengthened land-sea thermal gradient (Meehl and Washington 1993), more recent studies suggest that the enhanced 
atmospheric water vapor content with warming plays a far more prominent role (Douville et al. 2000; Ashrit et al. 2003). May (2004) suggested that increased atmospheric moisture flux into the South Asian region is responsible for the intensified future SASM rainfall under greenhouse warming. Ueda et al. (2006) also emphasized the role of the enhancement of moisture over the Indian Ocean source region and increased moisture transport into South Asia (SA).

One plausible explanation for increased monsoonal precipitation despite a weakening monsoonal circulation is the decoupling of thermodynamic and dynamic responses. In other words, the "thermodynamic" impact of increased precipitable water in a warmer atmosphere, rather than a "dynamical" response related to the strength of monsoon circulation, may be the primary factor behind increased monsoonal precipitation (Ashrit et al. 2003). By analyzing the contributions of the dynamic and thermodynamic components separately, Dairaku and Emori (2006) concluded that the thermodynamic changes are the primary factor in enhancing the daily mean SASM precipitation in global warming scenarios. Using the multimodel ensemble, Krishna Kumar et al. (2011) also considered thermodynamic effects rather than monsoonal circulation effects to be the principal reason for the overall increase in Indian monsoon rainfall in response to greenhouse gas forcing.

In the present study, we have analyzed projected future changes in the SASM in response to anthropogenic greenhouse gas increases in phase 3 of the Coupled Model Intercomparison Project (CMIP3) multimodel ensemble of climate model simulations. This study is a continuation and extension of Fan et al. (2010), which analyzed the historical behavior [climate of the twentiethcentury experiment (20C3M)] in the CMIP3 multimodel simulations. Here, the SASM behavior is analyzed in the same set of climate models, but for the twenty-first century simulations of the response to the A1B greenhouse gas emission scenario. The primary purpose of this study is to better understand the factors governing projected changes in SASM circulation and precipitation under future greenhouse forcing. In particular, we seek to establish the relative role of different contributions (e.g., diabatic heating versus dry static stability) to the governing energy balance, and to compare the energetics governing projected climate change with that which governs interannual variability.

In section 2, we review the so-called wind-precipitation paradox to explain the potential decoupling of the SASM circulation and precipitation and introduce a framework based on the thermodynamic energy equation for understanding the underlying energy and heat balance. In section 3 , we briefly describe the models, experiments, and general procedures applied for studying projected future changes in the SASM. In section 4 , we assess the projected twenty-first-century trends in the SASM circulation and precipitation, analyze the dynamical consistency of the models' response, and interpret the responses in the context of the thermodynamic energy budget for a select subset of simulations. We also examine the relationship between projected changes in the El Niño-Southern Oscillation (ENSO) and changes in the SASM. In section 5, we summarize the main conclusions of the study.

\section{Background}

\section{a. Competing effects of diabatic heating and dry static stability}

Neglecting nonlinear terms, the traditional omega equation in isobaric coordinates, as derived from the vorticity and thermodynamic equations, can be written as

$$
\left(\nabla^{2}+\frac{f_{0}^{2} p}{S_{p} R} \frac{\partial^{2}}{\partial p^{2}}\right) \omega=-\frac{1}{S_{p} c_{p}} \nabla^{2} J
$$

where $\omega\left(\mathrm{Pa} \mathrm{s}^{-1}\right)$ is the vertical velocity, $f_{0}\left(\mathrm{~s}^{-1}\right)$ is the Coriolis parameter, $S_{p} \equiv\left(R T / c_{p} p\right)-(\partial T / \partial p)=$ $-T(\partial \ln \theta / \partial p)\left(\mathrm{K} \mathrm{Pa}^{-1}\right)$ is the static stability parameter, $T(\mathrm{~K})$ is temperature, $\theta(\mathrm{K})$ is the potential temperature, $R\left(\mathrm{~J} \mathrm{~kg}^{-1} \mathrm{~K}^{-1}\right)$ is the gas constant for dry air, $c_{p}\left(\mathrm{~J} \mathrm{~K}^{-1} \mathrm{~kg}^{-1}\right)$ is the specific heat of dry air at constant pressure, and $J\left(\mathrm{~W} \mathrm{~kg}^{-1}\right)$ is the diabatic heating rate of the air per unit mass. Introducing $L$ and $\Delta p$ as the horizontal and vertical scales of $\omega$ variation, respectively, we can estimate the order of magnitude for the vertical velocity $\omega$,

$$
\omega \approx-\frac{L^{2}}{S_{p} c_{p}}\left(1+\frac{f_{0}^{2} p L^{2}}{S_{p} R(\Delta p)^{2}}\right)^{-1} \nabla^{2} J .
$$

As discussed in Fan et al. (2010), the changes in vertical velocity $\omega$-a reasonable measure of the monsoonal circulation - may be interpreted as a balance between various competing processes. In response to greenhouse warming, the diabatic heating rate $J$ tends to increase and the monsoonal trough deepens. As the warming is greater over the Indian subcontinent than the Indian Ocean, we may expect that the intensified land-ocean thermal gradient leads to increased monsoonal circulation. Moreover, the increased convective latent heating associated with enhanced monsoonal precipitation, which in turn is due to increased moisture content in the warmer 
climate, may further increase the diabatic heating rate $J$ in the region of the rising limb of the circulation. This further strengthens the ascending motion $(-\omega)$ and the associated monsoonal circulation. On the other hand, this increased midtropospheric latent heating released over the rising limb of the monsoonal circulation may induce an increase in the lower- (middle-) level dry static stability $S_{p}$, thus suppressing the upward motion $-\omega$ and the monsoonal circulation. These competing mechanisms provide a plausible explanation for the decoupling of the monsoonal circulation and precipitation trends in an anthropogenic global warming scenario.

\section{b. Thermodynamic energy equation}

The thermodynamic energy equation in isobaric coordinates can be expressed as

$$
\frac{\partial T}{\partial t}+u \frac{\partial T}{\partial x}+v \frac{\partial T}{\partial y}-S_{p} \omega=J / c_{p}
$$

where $u\left(\mathrm{~m} \mathrm{~s}^{-1}\right)$ and $v\left(\mathrm{~m} \mathrm{~s}^{-1}\right)$ are the zonal and meridional velocity respectively, and other variables are as defined in section $2 \mathrm{a}$. The local rate of change in temperature is governed by horizontal temperature advection $[u(\partial T / \partial x)+v(\partial T / \partial y)]$, adiabatic cooling $\left(-S_{p} \omega\right)$, and diabatic heating from convective latent heat release and radiative effects $(J)$. Let us assume that 1$)$ the latent heat is released uniformly in the air column within a certain depth, 2) the radiative effects comprise both radiative cooling under clear-sky conditions and downward radiative forcing from clouds, and 3) the combined radiative effects of both clear-sky and cloud conditions can be parameterized with a Newtonian cooling approximation. Under these assumptions, we explicitly partition the diabatic heating term $J$ into latent heating rate and Newtonian cooling in the column. The thermodynamic energy equation can then be written,

$\frac{\partial T}{\partial t}+u \frac{\partial T}{\partial x}+v \frac{\partial T}{\partial y}-S_{p} \omega=\frac{Q_{c}}{\rho h c_{p}}-\gamma\left(T-T_{E}\right)$,

where $\rho\left(\mathrm{kg} \mathrm{m}^{-3}\right)$ is air density, $h(\mathrm{~m})$ is the height of the column, $\gamma$ is the inverse of the radiative relaxation time scale, $T_{E}$ is temperature at equilibrium, and $Q_{c}\left(\mathrm{~W} \mathrm{~m}^{-2}\right)$ is the latent heating rate of the column per unit area.

\section{Models, experiments, and methodology}

\section{a. Model simulation details}

The climate model simulations examined in this study are taken from a suite of experiments using state of the art coupled atmosphere-ocean general circulation models
(AOGCMs) developed and run by leading modeling centers around the world. The simulations of past and projected future climate were performed for CMIP3, and the simulations output have been archived to form the "World Climate Research Programme (WCRP) CMIP3 multimodel dataset." Many of the key findings of this project were summarized by Working Group 1 of the Fourth Assessment Report (AR4) of the Intergovernmental Panel on Climate Change (IPCC).

In Fan et al. (2010), we focused on results for the historical (20C3M) CMIP3 simulations. Here, we have instead focused on simulations for the 720-ppm stabilization experiment [Special Report on Emissions Scenarios (SRES) A1B]. Of the full 24 models (60 realizations) archived for SRES A1B, a slightly smaller subset of 23 models (51 realizations) provided the suite of fields required for our analysis.

The various AOGCMs of the multimodel archive differ in their treatment of the coupled atmospheric, oceanic, sea ice, and land surface components of the Earth system. Moreover, the different models vary with respect to whether and how various physical and chemical processes are represented, including atmospheric chemistry, interactive biochemistry, aerosols and their effects, dynamical vegetation, and ice sheets physics. Consider for example the representation of aerosols, which is potentially quite important for the behavior of the SASM (see e.g., Fan et al. 2010). In some models only the direct radiative effect of sulfate aerosols is included [e.g., Goddard Institute for Space Studies Atmosphere-Ocean Model (GISS-AOM) and the Meteorological Research Institute Coupled General Circulation Model, version 2.3.2 (MRICGCM2.3.2)]. Other models include various aerosol species but with only the direct effect from scattering and absorption [e.g., Geophysical Fluid Dynamics Laboratory Climate Model version 2.0 (GFDL CM2.0) and Institute of Numerical Mathematics Coupled Model, version 3.0 (INM-CM3.0)] or only sulfate aerosols with both direct and indirect effects (e.g., ECHAM5/Max Planck Institute Ocean Model (MPI-OM) and L'Institut Pierre-Simon Laplace Coupled Model, version 4 (IPSL CM4)]. Several models, however, include not only different aerosol species but both their direct and indirect effects [e.g., GISS Model E-H (GISS-EH), GISS Model E-R (GISS-ER), the Model for Interdisciplinary Research on Climate 3.2, highresolution version $\{$ MIROC3.2(hires) $\}$, and MIROC3.2 medium-resolution version $\{$ MIROC3.2(medres) $\}$ ].

In the 720-ppm stabilization (SRES A1B) CMIP3 experiments, each model simulation is initialized using the end of the historical (20C3M) simulations and subsequently subject to forcing by the SRES A1B future emission scenario. The key assumptions for SRES A1B scenario can be summarized as (i) a more integrated 
future world of rapid economic growth, (ii) low global population growth, (iii) quick spread of new and efficient technologies, and (iv) economic and cultural convergence with a substantial reduction in regional differences (Nakićenović et al. 2000). The two main anthropogenic forcings, greenhouse gases, and sulfate aerosols, which may have had opposing impacts on historical trends in the SASM (see e.g., Fan et al. 2010), exhibit very different trends in the SRES A1B scenario. While the estimated $\mathrm{CO}_{2}$ radiative forcing increases continuously from the end of the twentieth century to the end of the twenty-first century, direct radiative forcing by sulfate aerosols only increases through 2020 and then gradually declines to the end of the twenty-first century. The total radiative forcing from greenhouse gases and both direct and indirect aerosol forcing produces a consistent increasing trend throughout the end of the twenty-first century (see appendix II of Houghton et al. 2001). This projected anthropogenic forcing pathway suggests increasing dominance of greenhouse gas over sulfate aerosol forcing over the course of the A1B simulations.

\section{b. Diagnosis of monsoon influences}

We employ the same formalisms for defining the SASM circulation and precipitation used in previous studies (Fan et al. 2009, 2010). In particular, we employ a so-called integrative monsoon index (IMI), based on the leading pattern common to a suite of relevant atmospheric fields (sea level pressure, vertical shear of zonal wind, and vertical shear of meridional wind) to define the strength of the SASM circulation (details can be found in Fan et al. 2009). Positive IMI anomalies, which represent stronger monsoonal circulation, are associated with a broad negative sea surface pressure anomalies over South Asia, positive vertical shear of the zonal wind anomalies over the region $5^{\circ}-20^{\circ} \mathrm{N}, 40^{\circ}-110^{\circ} \mathrm{E}$, and a tripolar structure in the vertical shear of the meridional wind anomalies. In fact, the IMI defined by application of our approach to the National Centers for Environmental Prediction (NCEP) reanalysis data is significantly correlated with each of three existing SASM measures [Webster and Yang index (Webster and Yang 1992); Monsoon Hadley index (Goswami et al. 1999); and allIndia monsoon rainfall index (Parthasarathy et al. 1992)] at the two-sided $p=0.01$ level $(r=0.528,0.402$, and 0.443 , respectively) during the latter half of the twentieth century. We applied two metrics of SASM precipitation, which include boreal summer [June-August, (JJA)] rainfall averaged over (i) the Indian subcontinent only (Parthasarathy et al. 1992, 1994) and (ii) a broader South Asian region $\left(8.5^{\circ}-30^{\circ} \mathrm{N}, 65^{\circ}-100^{\circ} \mathrm{E}\right)$ (Dairaku and Emori 2006).

For the purpose of diagnosing the relative roles of different factors governing the strength of the SASM circulation, we produced correlation maps based on regressing the SASM circulation index (i.e., IMI) against three JJA mean monsoon-related fields: dry static stability measured by $S_{p}$, midtropospheric latent heating, and vertical velocity $\omega$ over the region $\left(0^{\circ}-60^{\circ} \mathrm{N}, 40^{\circ}-105^{\circ} \mathrm{E}\right.$ ) (we estimated the midtropospheric latent heating based on the assumption that precipitation is associated with deep convection and that all condensed precipitable water falls out as precipitation). These analyses were performed at the surface level for precipitation and at three tropospheric pressure levels [i.e., lower (850), middle (500), and upper $(300 \mathrm{hPa})$ levels] for the dry static stability $\left(S_{p}\right)$ and the vertical velocity $(\omega)$. To reduce the impact of small-scale spatial features in the precipitation and $\omega$ fields, we smoothed both fields before further analysis [these fields were spatially averaged over blocks of 25 gridboxes for high-resolution models, e.g., Community Climate System Model, version 3 (CCSM3), MIROC3.2(hires), and 9 gridboxes for medium-resolution models, e.g., Canadian Centre for Climate Modelling and Analysis (CCCma) Coupled General Circulation Model, version 3.1 (CGCM3.1) (T63), and Centre National de Recherches Météorologiques Coupled Global Climate Model, version 3 (CNRM-CM3)].

\section{c. Thermodynamic energy budget calculations}

The time-averaged thermodynamic energy equation can be written,

$$
\frac{\overline{\partial T}}{\partial t}+u \frac{\overline{\partial T}}{\partial x}+v \frac{\overline{\partial T}}{\partial y}-\overline{S_{p} \omega}=\frac{\overline{Q_{c}}}{\rho h c_{p}}-\gamma\left(\bar{T}-\overline{T_{E}}\right),
$$

where the overbar denotes a time average over some specified interval. To investigate the relative contribution of each of these terms to trends in the SASM, we consider the differences between an appropriately chosen "late" and "early" interval:

$$
\begin{aligned}
& \delta\left(\frac{\overline{\partial T}}{\partial t}\right)+\delta\left(u \frac{\partial \bar{T}}{\partial x}+v \frac{\overline{\partial T}}{\partial y}\right)-\overline{S_{p}} \delta \bar{\omega}-\bar{\omega} \delta \overline{S_{p}} \\
& \quad=\delta\left(\overline{\frac{Q_{c}}{\rho h c_{p}}}\right)-\gamma \delta \bar{T} .
\end{aligned}
$$

In this equation [(6)], the changes in the products between mean and perturbation [i.e., $\delta\left(\overline{\overline{S_{p}}} \omega^{\prime}\right)$ and $\delta\left(\overline{S_{p}^{\prime} \bar{\omega}}\right)$ ] and the change in the product between perturbations [i.e., $\left.\delta\left(\overline{S_{p}^{\prime} \omega^{\prime}}\right)\right]$ have been ignored. In the calculations conducted later in section $4 \mathrm{c}$, the change in the local rate of change in temperature is at least an order of magnitude smaller than the changes in the other terms and 

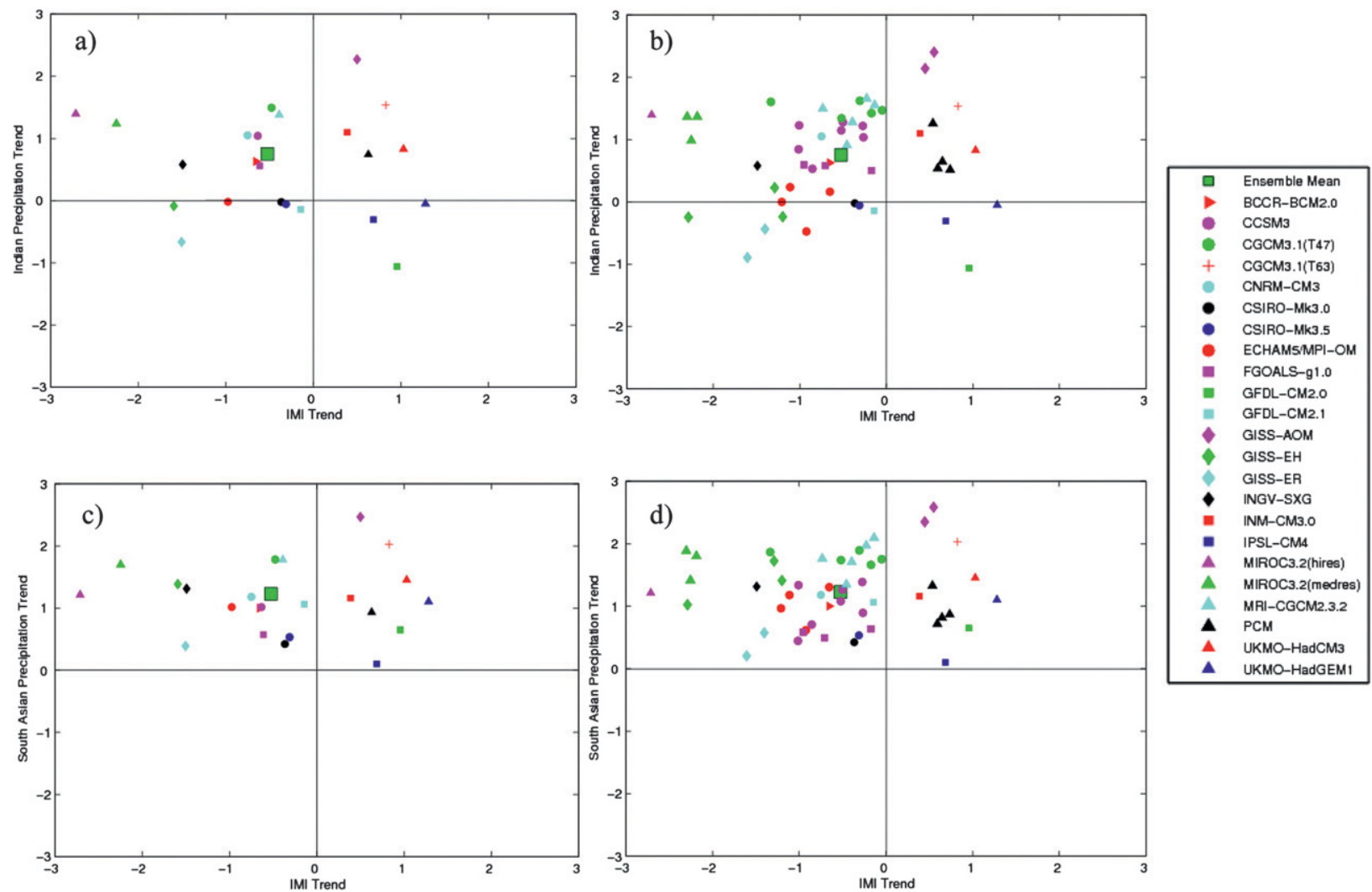

FIG. 1. Trends in SASM behavior over the twenty-first century based on A1B scenario of the CMIP3 multimodel simulations. Horizontal axes denote circulation strength as measured by IMI while vertical axes denote SASM-related precipitation. The ensemble mean (large green square) over all models/simulations is shown for comparison. (a) Results for all 23 AOGCMs with results from multiple realizations averaged to give a single estimate for each model; the model precipitation is defined as the mean over the Indian grid boxes (latitude and longitude range or section reference). (b) As in (a), but for all 51 individual realizations. (c) As in (a), but defining the model precipitation as the mean over broader South Asian region $\left(8.5^{\circ}-30^{\circ} \mathrm{N}, 65^{\circ}-100^{\circ} \mathrm{E}\right)$. (d) As in (b), but defining the model precipitation as the mean over broader South Asian region.

can therefore be neglected $[\delta(\overline{\partial T} / \partial t) \approx 0]$. In the NCEPNational Center for Atmospheric Research (NCAR) reanalysis, the difference in this term between the last $10 \mathrm{yr}$ and first $10 \mathrm{yr}$ of 1948-2000 interval averaged over three pressure levels is only $4.503 \times 10^{-8} \mathrm{~K} \mathrm{~s}^{-1}$, far smaller than the changes in other terms that are of the order $10^{-6}$ or $10^{-7} \mathrm{~K} \mathrm{~s}^{-1}$. We further assume that 1) latent heat is released uniformly between 850 and $300 \mathrm{hPa}$ within an approximate column depth of $8.5 \mathrm{~km}$, and 2) the radiative relaxation time scale is approximately 30 days with a range from 20 to 40 days, and accordingly the value of $\gamma$ is $1 / 30$ with an uncertainty range from $1 / 40$ to $1 / 20$.

\section{Analysis of modeled SASM behavior}

\section{a. Trends in SASM circulation and precipitation}

Figure 1 illustrates the distribution of trends in SASM circulation and precipitation in the A1B twenty-firstcentury projections. SASM circulation is measured by the IMI, while precipitation is measured by JJA mean precipitation averaged both over the Indian subcontinent (Figs. 1a,b) and larger South Asian region (Figs. 1c,d). Results are shown both for the 23 models (where multiple realizations of a given model are averaged to yield a single best estimate-Figs. 1a,c) and all 51 simulations (Figs. 1b,d). In addition, by averaging over all models and simulations, the ensemble mean of the trends in IMI and the SASM precipitation (large green square) is provided for comparison.

By comparison with the large spread seen in the historical (20C3M) simulations (see Fig. 3 in Fan et al. 2010), the trends for the A1B projections show a far more consistent tendency toward a weakened SASM circulation and increased SASM precipitation (this is evident from the clustering of the simulations in the upper-left part of the four panels). Moreover, unlike the 20C3M simulations, there is far greater consistency among multiple realizations of the same model [e.g., CCSM3, MIROC3.2(medres), etc], suggesting that, unlike the historical period, the forced signal dominates 
over the role of internal variability. All of 10 ( 8 out of 10 ) models with multiple realizations show consistent trends in the IMI (Indian precipitation) in SRES A1B projections versus only 2 out of 10 ( 4 out of 10 ) in 20C3M simulations.

The ensemble mean over all models and simulations indicates a weakening SASM circulation (i.e., negative trend in IMI) and increasing SASM precipitation. Here, 15 out of 23 models (Fig. 1a) (39 out of 51 realizations; Fig. 1b) exhibit a decreasing trend in the IMI, with trends significant at the two-sided $p=0.05$ level for 21 of the realizations. SASM precipitation shows an increasing trend for 14 (Fig. 1a) and all 23 (Fig. 1c) models, using the average over the Indian subcontinent and larger South Asian region, respectively. These conclusions hold for 39 (Fig. 1b) and all 51 realizations (Fig. 1d), respectively. These trends are statistically significant at the two-sided $p=0.05$ level for 27 and 40 of the 51 realizations respectively. That 12 realizations show increasing precipitation over the broader SASM region while showing decreasing precipitation over India indicates the importance of trends in surrounding regions. For example, the increased precipitation over the south Arabian Sea, the south and east Bay of Bengal, and the North Indian Ocean effectively offsets the decreased precipitation concentrated over northeast India in Commonwealth Scientific and Industrial Research Organisation (CSIRO) models. It is also important to note that in spite of the quite different or even opposite trends in the SASM circulation and SASM-related precipitation for each model realization, all but a very few [e.g., MIROC3.2(hires) and MIROC3.2(medres)] of these model simulations indicate highly significant positive correlations between the IMI and the summer monsoon precipitation averaged over both Indian subcontinent and broader South Asian region (Table 1 ). This observation suggests that monsoon circulation and precipitation are closely related on interannual time scales.

\section{b. Patterns of monsoonal influence on atmospheric variables}

Patterns of monsoonal influence on various atmospheric fields were determined by computing correlation maps of these fields against the IMI. These analyses were performed for seven climate models classified as "best performing" (see Table 2) with respect to their ability to reproduce the observed climatological mean state and interannual variability of the SASM as measured by Indian precipitation (Fan et al. 2010). As varying realizations of the same model showed similar patterns (with the notable exception of one realization of GISS-EH), it suffices to examine the patterns for a representative realization of each model (see Table 2). Because of the
TABLE 1. Correlations between the SASM IMI and JJA mean precipitation averaged over the Indian subcontinent and broader South Asian region over the twenty-first century for the 23 models (51 realizations). Correlations that are statistically significant at the two-tailed $p=0.01$ level ( $p=0.1$ level) are indicated by boldface (italics).

\begin{tabular}{|c|c|c|c|}
\hline Models & Runs & $\begin{array}{l}\text { IMI/Indian } \\
\text { precipitation }\end{array}$ & $\begin{array}{c}\text { IMI/SA } \\
\text { precipitation }\end{array}$ \\
\hline BCCR-BCM2.0 & Run1 & 0.254 & 0.274 \\
\hline \multirow[t]{7}{*}{ CCSM3 } & Run1 & 0.420 & 0.567 \\
\hline & Run2 & 0.509 & 0.541 \\
\hline & Run3 & 0.421 & 0.455 \\
\hline & Run5 & 0.485 & 0.570 \\
\hline & Run6 & 0.622 & 0.620 \\
\hline & Run7 & 0.506 & 0.576 \\
\hline & Run9 & 0.585 & 0.666 \\
\hline \multirow{5}{*}{ CGCM3.1 (T47) } & Run1 & 0.526 & 0.554 \\
\hline & Run2 & 0.437 & 0.536 \\
\hline & Run3 & 0.085 & 0.147 \\
\hline & Run4 & 0.345 & 0.370 \\
\hline & Run5 & 0.544 & 0.466 \\
\hline CGCM3.1 (T63) & Run1 & 0.770 & 0.742 \\
\hline CNRM-CM3 & Run1 & 0.496 & 0.652 \\
\hline CSIRO Mk3.0 & Run1 & 0.811 & 0.798 \\
\hline CSIRO Mk3.5 & Run1 & 0.758 & 0.624 \\
\hline \multirow[t]{4}{*}{ ECHAM5/MPI-OM } & Run1 & 0.783 & 0.371 \\
\hline & Run2 & 0.748 & 0.292 \\
\hline & Run3 & 0.848 & 0.414 \\
\hline & Run4 & 0.749 & 0.281 \\
\hline \multirow[t]{3}{*}{ FGOALS-g1.0 } & Run1 & 0.886 & 0.923 \\
\hline & Run2 & 0.796 & 0.865 \\
\hline & Run3 & 0.713 & 0.774 \\
\hline GFDL CM2.0 & Run1 & 0.103 & 0.277 \\
\hline GFDL CM2.1 & Run1 & 0.660 & 0.500 \\
\hline \multirow[t]{2}{*}{ GISS-AOM } & Run1 & 0.497 & 0.518 \\
\hline & Run2 & 0.512 & 0.552 \\
\hline \multirow[t]{3}{*}{ GISS-EH } & Run1 & 0.393 & 0.150 \\
\hline & Run2 & 0.377 & 0.066 \\
\hline & Run3 & -0.026 & -0.325 \\
\hline \multirow{2}{*}{ GISS-ER } & Run2 & 0.480 & 0.178 \\
\hline & Run4 & 0.657 & 0.433 \\
\hline INGV-SXG & Run1 & 0.477 & 0.014 \\
\hline INM-CM3.0 & Run1 & 0.233 & 0.419 \\
\hline IPSL CM4 & Run1 & 0.329 & 0.679 \\
\hline MIROC3.2(hires) & Run1 & -0.189 & -0.003 \\
\hline \multirow[t]{3}{*}{ MIROC3.2(medres) } & Run1 & -0.182 & -0.150 \\
\hline & Run2 & -0.402 & -0.282 \\
\hline & Run3 & -0.176 & -0.009 \\
\hline \multirow[t]{5}{*}{ MRI-CGCM2.3.2 } & Run1 & 0.711 & 0.573 \\
\hline & Run2 & 0.616 & 0.527 \\
\hline & Run3 & 0.723 & 0.490 \\
\hline & Run4 & 0.747 & 0.616 \\
\hline & Run5 & 0.562 & 0.459 \\
\hline \multirow[t]{4}{*}{ PCM } & Run1 & 0.440 & 0.476 \\
\hline & Run2 & 0.376 & 0.532 \\
\hline & Run3 & 0.431 & 0.607 \\
\hline & Run4 & 0.513 & 0.484 \\
\hline UKMO HadCM3 & Run1 & 0.770 & 0.728 \\
\hline UKMO HadGEM1 & Run1 & 0.284 & 0.499 \\
\hline
\end{tabular}


TABLE 2. Listing of 23 AOGCMs used in this study. The seven models (18 realizations) selected for detailed analysis in section $4 \mathrm{~b}$ are indicated by italics. The seven realizations (each one from one of the seven selected models) further analyzed in section $4 \mathrm{c}$ are indicated by boldface.

\begin{tabular}{lll}
\hline \hline \multicolumn{1}{c}{ Models } & \multicolumn{1}{c}{ Acronyms } \\
\hline Bjerknes Centre for Climate Research Bergen Climate Model, version 2.0 & BCCR-BCM2.0 & Run1 \\
NCAR Community Climate System Model, version 3.0 & CCSM3 & Run1
\end{tabular}

NCAR Community Climate System Model, version 3.0

$\operatorname{CCSM} 3$

CCCma Coupled Global Climate Model, version 3.1, T47 resolution version

CCCma Coupled Global Climate Model, version 3.1, T63 resolution version

Météo-France/Centre National de Recherches

Météorologiques Coupled Global Climate Model, version 3

CSIRO Mark 3.0

CSIRO Mark 3.5

Max Planck Institute for Meteorology Coupled Atmosphere-Ocean General

Circulation Model

Flexible Global Ocean-Atmosphere-Land System Model gridpoint

version 1.0 (FGOALS-g1.0)

Geophysical Fluid Dynamics Laboratory Global Coupled Climate Model, version 2.0

Geophysical Fluid Dynamics Laboratory Global Coupled Climate Model, version 2.1

National Aeronautics and Space Administration (NASA) Goddard

Institute for Space Studies Coupled Atmosphere-Ocean Model

NASA Goddard Institute for Space Studies Model E-H

NASA Goddard Institute for Space Studies Model E-R

Instituto Nazionale di Geofisica e Vulcanologia (INGV) Scale Interaction Experiment (SXG)

Institute for Numerical Mathematics Coupled Model, version 3.0 (INM-CM3.0)

Institut Pierre Simon Laplace Climate System Model, version 4

Model for Interdisciplinary Research on Climate, version 3.2, high-resolution version

Model for Interdisciplinary Research on Climate, version 3.2, medium-resolution version

MRI Coupled Global Climate Model, version 2.3.2

NCAR Parallel Climate Model

Third Climate Configuration of the Met Office (UKMO) Unified Model (HadCM3)

Hadley Centre Global Environmental Model, version 1 (HadGEM1)
CGCM3.1 (T47)

M3.1 (T63)

CNRM-CM3

CSIRO Mk3.0

CSIRO Mk3.5

ECHAM5/MPI-OM

Run1

Run1

Run2

Run3

Run4

FGOALS-g1.0 Run1

Run2

Run3

GFDL CM2.0 Run1

GFDL CM2.1 Run1

GISS-AOM Run1

Run2

GISS-EH Run1

Run2

Run3

GISS-ER

Run2

Run4

INGV-SXG Run1

INM-CM3.0 Run1

IPSL CM4 Run1

MIROC3.2(hires) RunI

MIROC3.2(medres) Run1

Run2

Run3

MRI-CGCM2.3.2 Run1

Run2

Run3

Run4

Run5

Run1

Run2

Run3

Run4

UKMO HadCM3 Run1 UKMO HadGEM1 Run1 similarity between the two GISS models (GISS-EH and GISS-ER) and between the two MIROC3.2 models [MIROC3.2(hires) and MIROC3.2(medres)], correlation patterns were shown for only one realization in each of those cases. Figures 2-6 show the resulting patterns for (i) dry static stability $\left(S_{p}\right)$, (ii) precipitation, and (iii) vertical velocity $(\omega)$ for five selected realizations. 
(a)
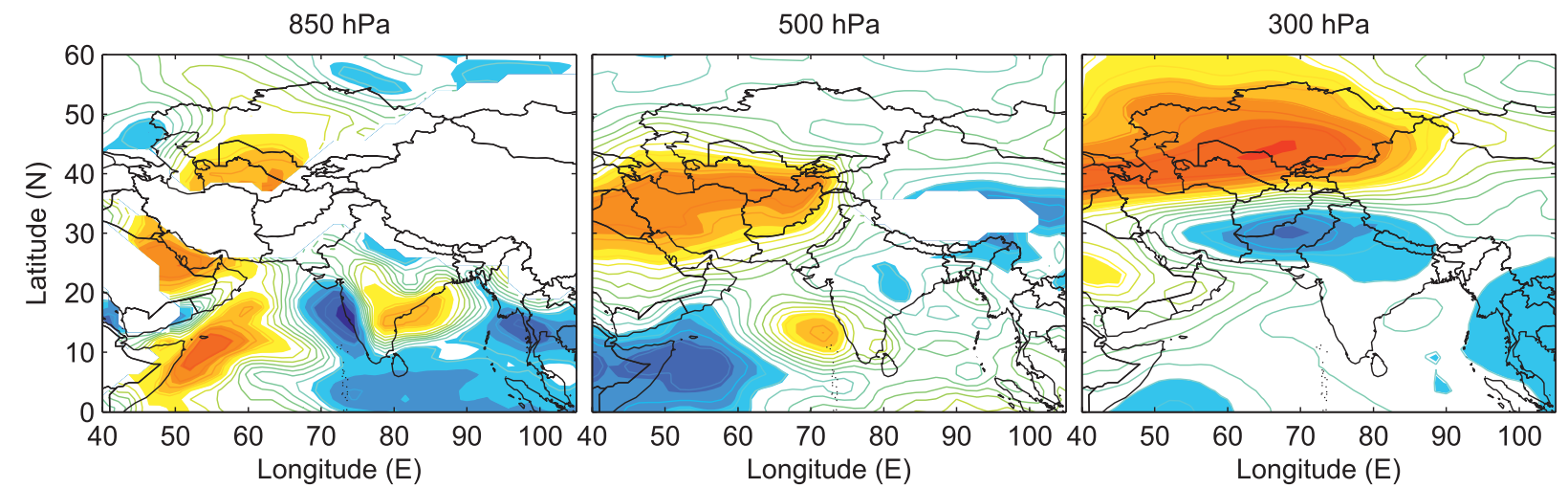

(b)

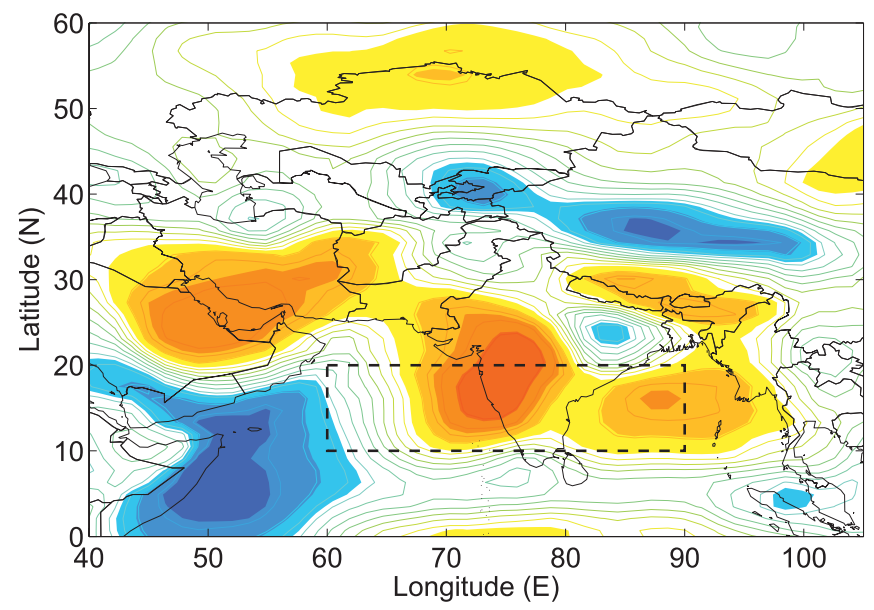

(c)
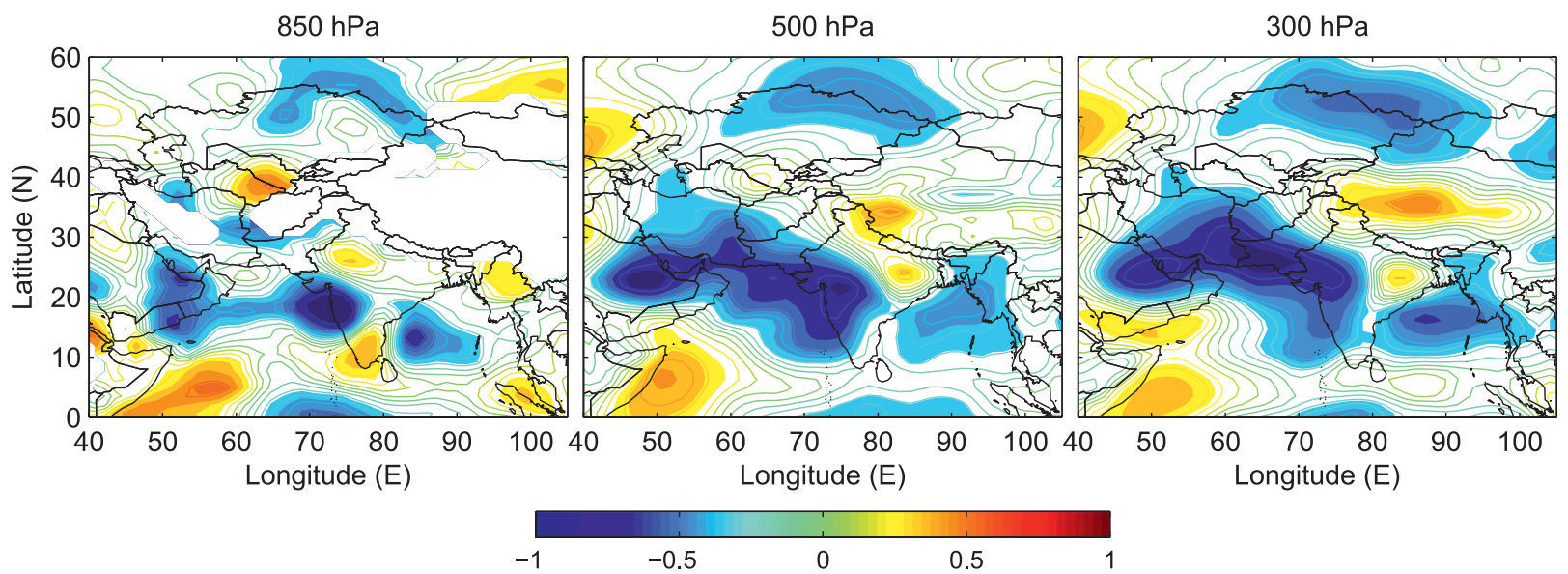

FIG. 2. Summer correlation patterns of the SASM IMI against monsoon-related fields (a) dry static stability $\left(S_{p}\right)$, (b) precipitation, and (c) vertical velocity $(\omega)$ for a single realization (Table 2 ) of CCSM3 during the 2000-99 interval. The South Asian region $\left(10^{\circ}-20^{\circ} \mathrm{N}\right.$, $60^{\circ}-90^{\circ} \mathrm{E}$ ) used in the thermodynamic energy budget analysis of section 4.3 is denoted by the box in Fig. $2 \mathrm{~b}$.

\section{1) DRY STATIC STABILITY}

The dry static stability patterns for CCSM3 indicate that positive IMI anomalies (i.e., strengthened SASM circulation) are associated with increased low-level (i.e., $850 \mathrm{hPa}$ ) dry static stability over most parts of the Indian subcontinent and the western part of the Bay and Bengal, increased midlevel (i.e., $500 \mathrm{hPa}$ ) dry static stability 
(a)
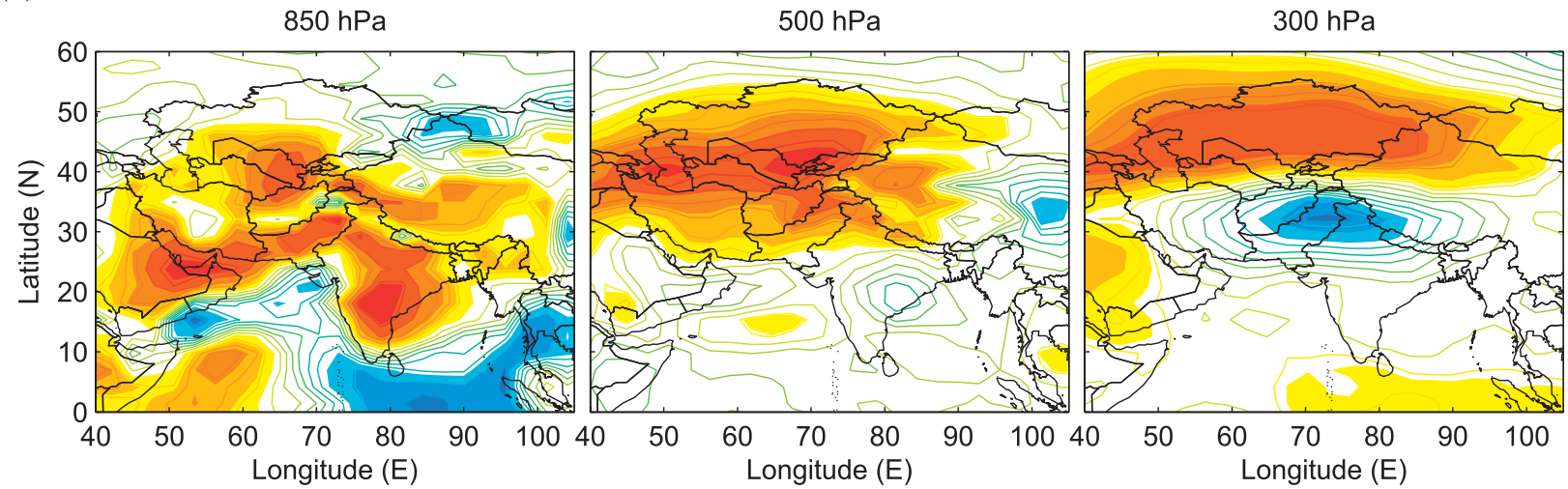

(b)

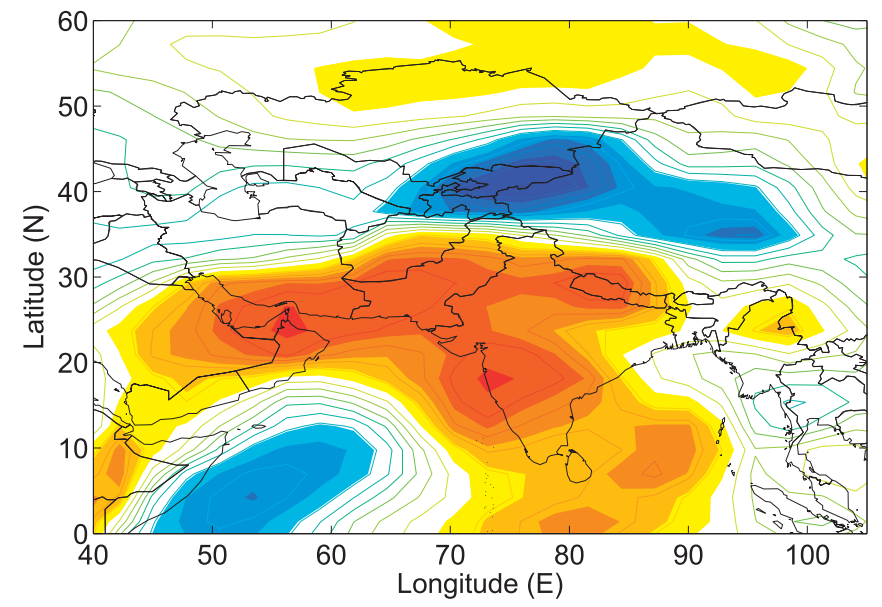

(c)

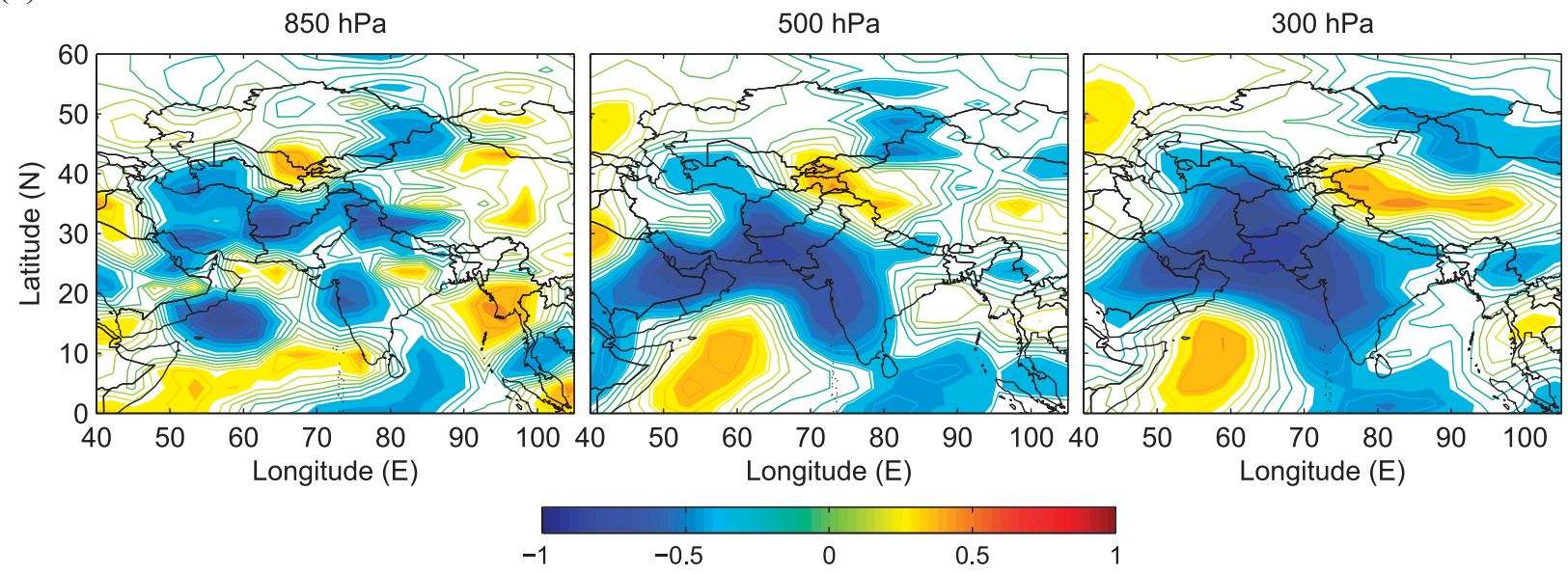

FIG. 3. As Fig. 2, but for a realization of CGCM3.1 (T63) during the 2001-2100 interval.

over the Arabian Sea, decreased midlevel dry static stability in central India, and decreased upper-level (i.e., $300 \mathrm{hPa}$ ) dry static stability over South Asian lands and surrounding oceans (Fig. 2a). Generally similar patterns are found for CGCM3.1 (T63) and CNRM-CM3 (Figs. 3a and 4a). However, the positive impact on dry static stability is greater, extending to all of India in the lower troposphere. According to Student $t$ test, the correlation coefficient $r=0.257$ (sample size $N=100$ ) is statistically significant at two-tailed $p=0.01$ level. Regions where 
(a)
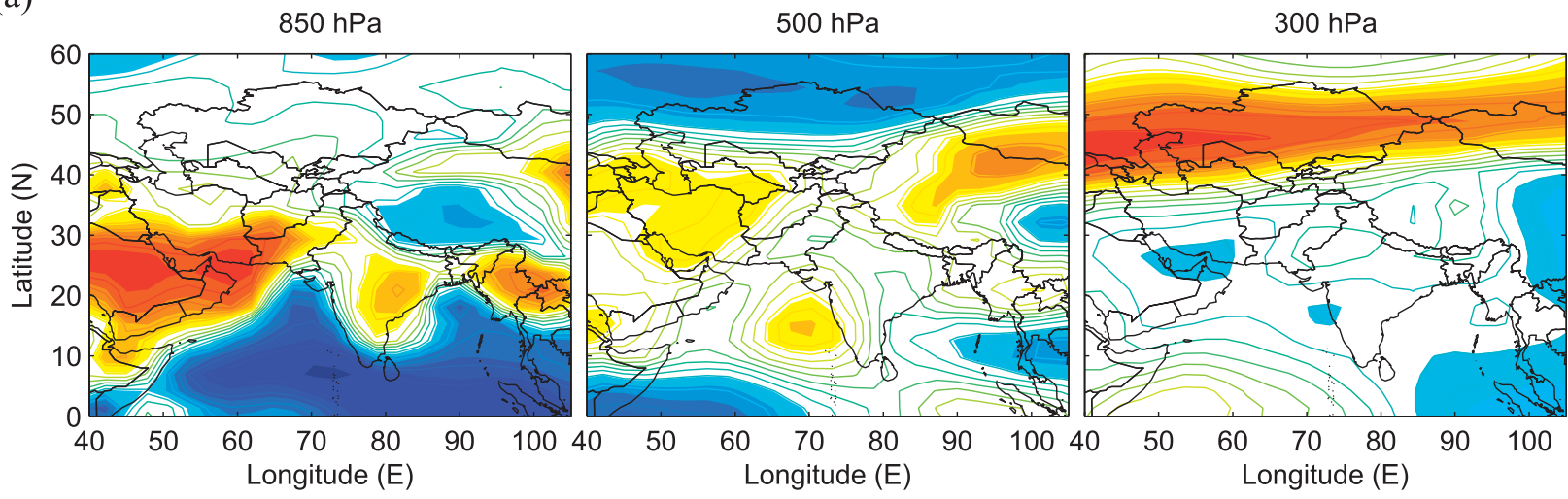

(b)

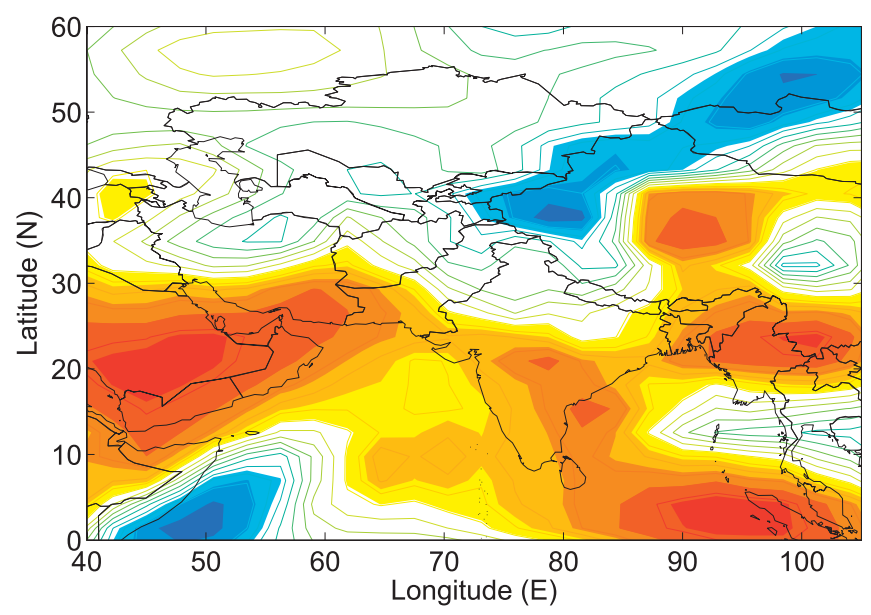

(c)
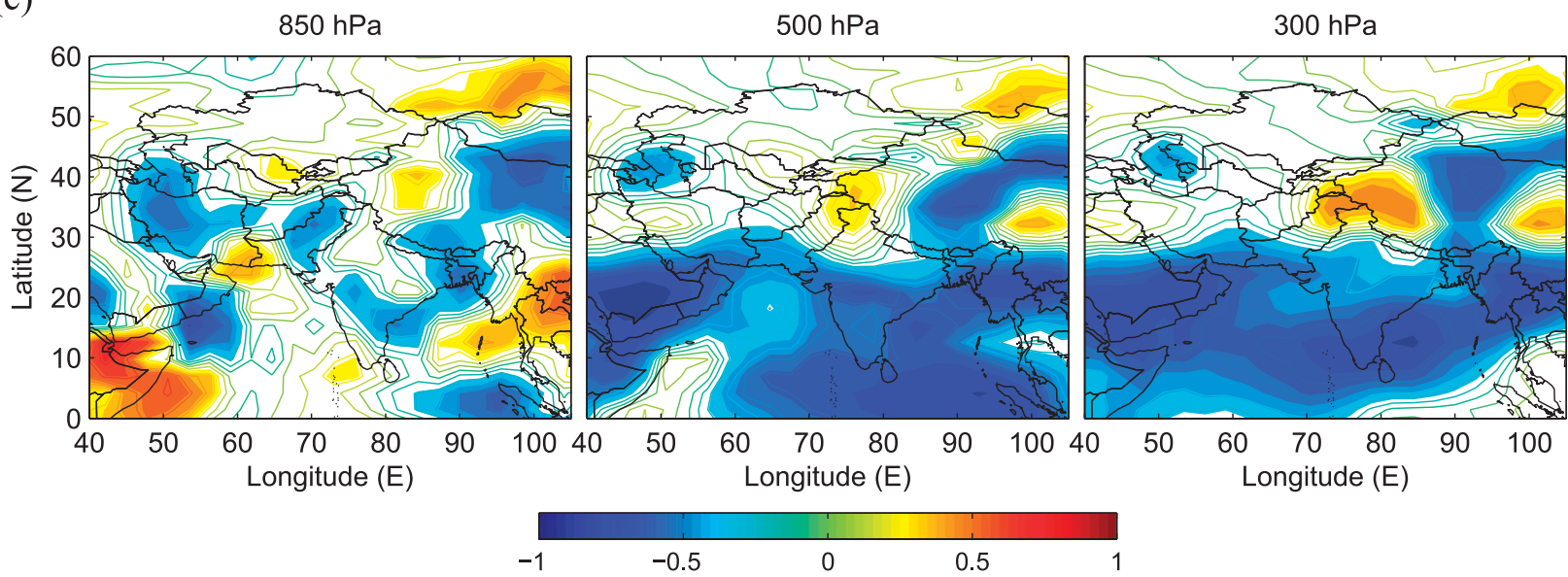

FIG. 4. As Fig. 2, but for a realization of CNRM-CM3 during the 2000-2100 interval.

the correlation is significant are highlighted with shading here and in similar subsequent figures.

Similar results are also found for the two GISS models (i.e., GISS-EH and GISS-ER) with certain notable exceptions. In one realization of GISS-EH, positive IMI anomalies are associated with increased low-level dry static stability over only north India, increased midlevel dry static stability over north India and the northern part of the Arabian Sea, and decreased upper-level dry static stability over South Asia (Fig. 5a). Similarly, for one realization of GISS-ER, positive IMI anomalies are associated with increased low-level dry static stability over 
(a)
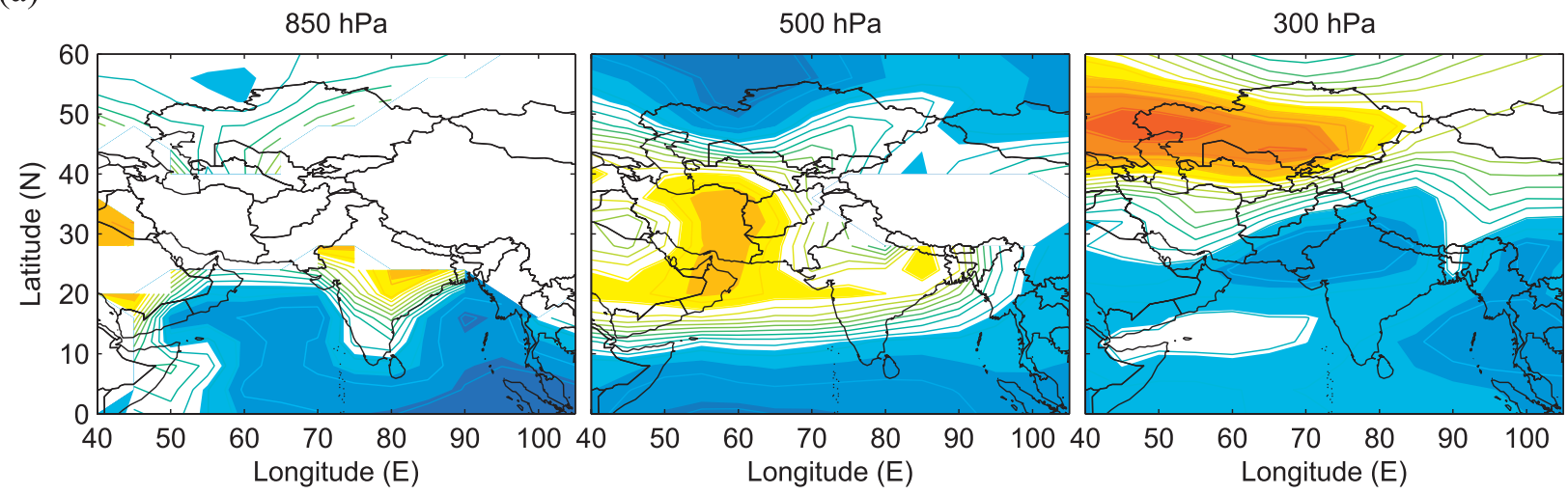

(b)

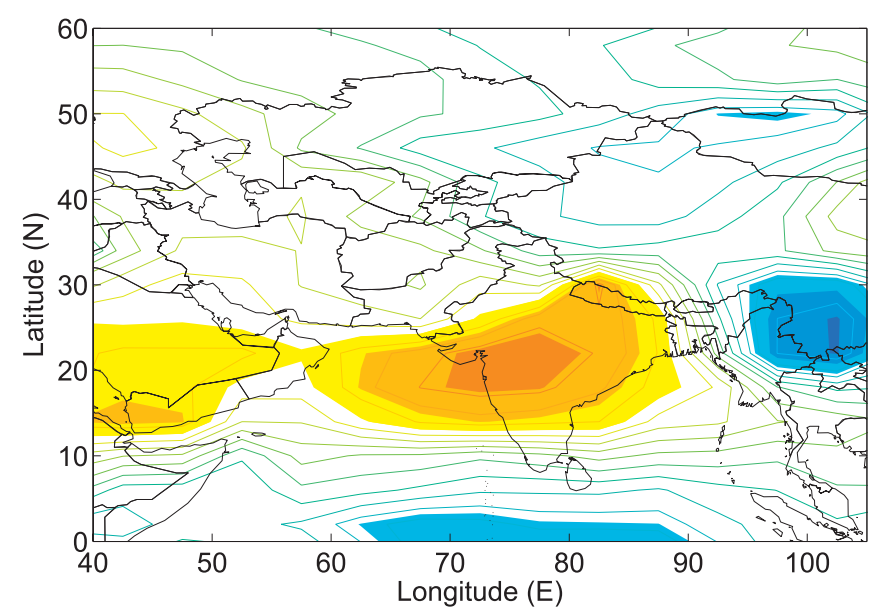

(c)
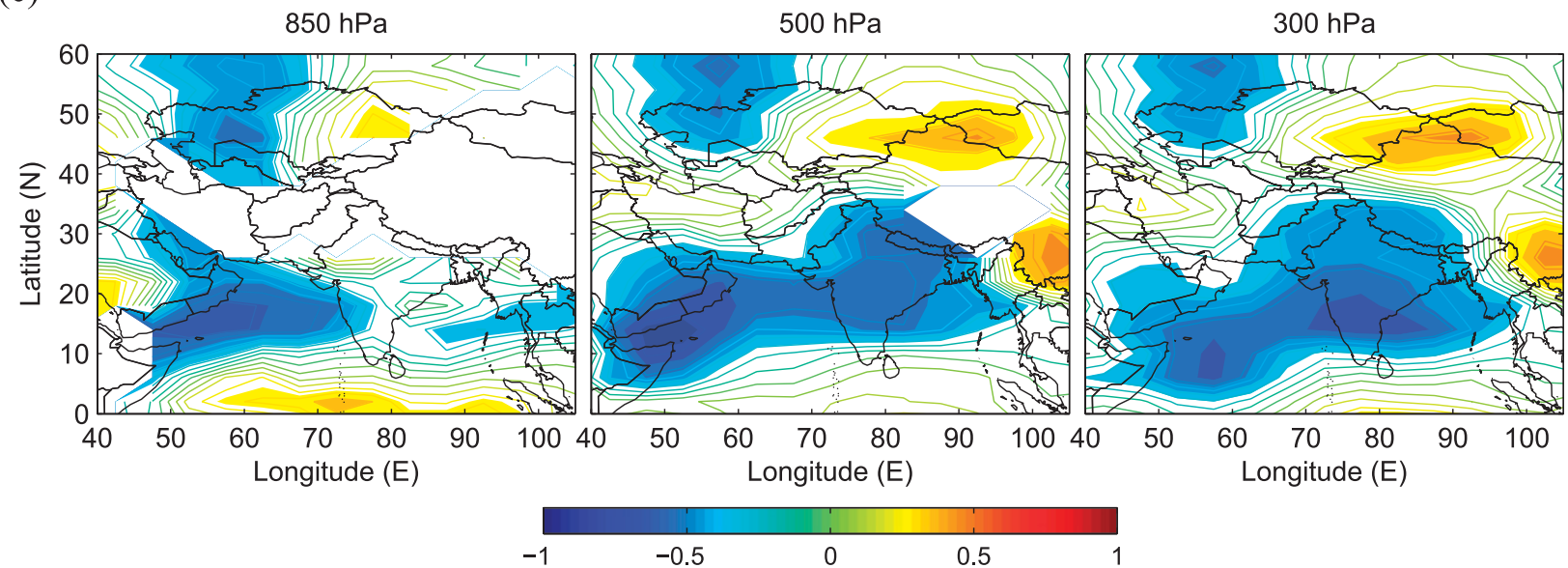

FIG. 5. As Fig. 2, but for a realization of GISS-EH during the 2000-2099 interval.

a small region over east India and the east coast of India (not shown).

The patterns of influence on dry static stability are quite different for the MIROC3.2 models [i.e., MIROC3.2(hires) and MIROC3.2(medres)]. There are only very slight and barely discernible positive correlations between the IMI and low-level dry static stability over a small area in central India, and negative correlations appear almost over the entire SASM region throughout all three tropospheric pressure levels (Fig. 6a). 
(a)
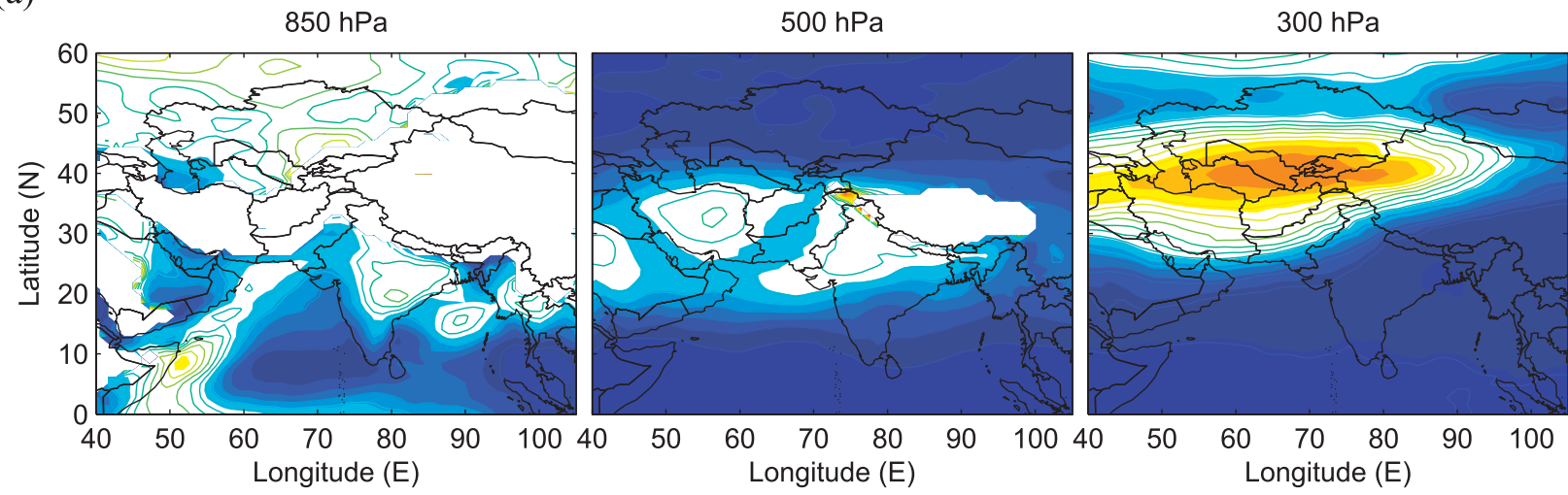

(b)

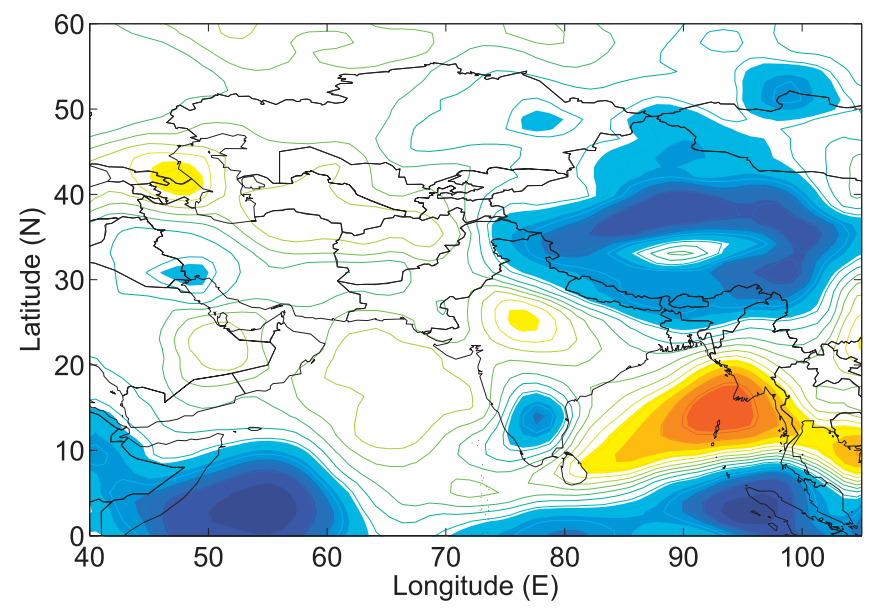

(c)
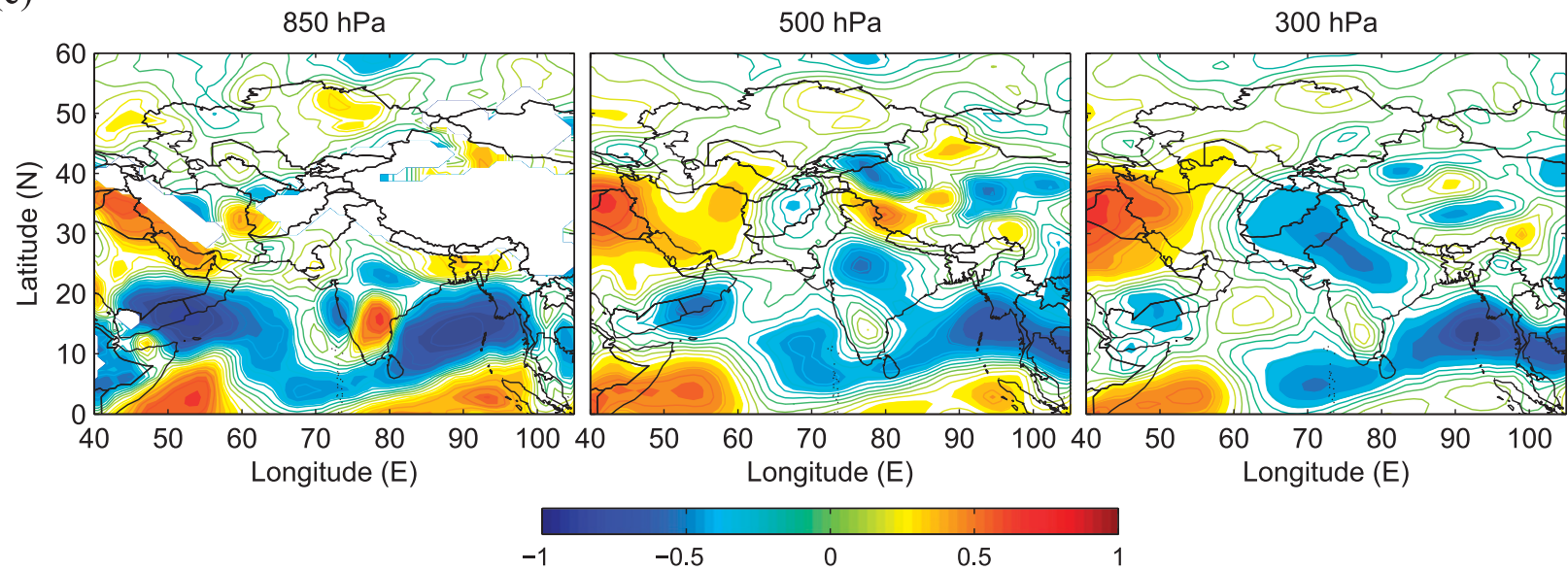

FIG. 6. As Fig. 2, but for a realization of MIROC3.2(hires) during the 2001-2100 interval.

\section{2) Precipitation And convective Latent HEATING}

The precipitation (and latent heating) patterns for CCSM3 indicate that positive IMI anomalies are accompanied by enhanced precipitation over most parts of
India except for a small area in the northeast, the eastern part of the Arabian Sea, and the Bay of Bengal (Fig. 2b). In CGCM3.1 (T63) and CNRM-CM3, increased precipitation associated with positive IMI anomalies are still evident over most parts of the Indian subcontinent, some parts of the Arabian Sea and the Bay of Bengal, 
but are also seen over the central and eastern North Indian Ocean (Figs. 3b and 4b). Comparing Figs. 2b, 3b, and $4 \mathrm{~b}$ with Figs. $2 \mathrm{a}, 3 \mathrm{a}$, and $4 \mathrm{a}$, we find that positive IMI anomalies are associated with increased precipitation over most parts of India and some parts of the Bay of Bengal that coincide with increased low-level dry static stability, implying that increased midtropospheric latent heating leads to stabilization of the lower troposphere.

GISS-EH (GISS-ER) patterns show intensified precipitation and correspondingly increased midtropospheric latent heating associated with positive IMI anomalies over almost the entire India, the Arabian Sea (the eastern and northern part of the Arabian Sea), and the western and northern part of the Bay of Bengal (the Bay of Bengal), and decreased precipitation over the North Indian Ocean (Fig. 5b and not shown). Again, the increased low-level dry static stability associated with positive IMI anomalies evident in Fig. 5a, though constrained to a smaller region than that the other models discussed previously, might also be induced by increased midtropospheric heating but competes with the latent heating to determine the monsoon circulation.

In MIROC3.2(hires), there are significant (moderate) positive correlations between the IMI and precipitation over the Bay of Bengal (the northern India and the Arabian Sea), but negative correlations over the southern tip of the Indian subcontinent and the North Indian Ocean (Fig. 6b). Similar patterns are also found for MIROC3.2(medres), but the positive correlations are much less significant (not shown). According to the correlation patterns of low-level dry static stability against IMI shown earlier in Fig. 6a, the possible increased dry static stability accompanied by positive IMI anomalies over parts of India might also be induced by intensified midtropospheric latent heating over those regions.

In summary, our analysis of the variations in the precipitation and dry static stability associated with the IMI anomalies in these seven model realizations indicate that, on interannual time scales, the convective heating effect dominates over the dry static stability effect to determine the strength of the SASM circulation.

\section{3) Vertical VELOCITY}

We would expect that the vertical velocity, indicative of the strength of the ascending and descending branch of the circulation, changes in the same way as the monsoon circulation. For these vertical velocity changes to be consistent with convectively induced changes in the static stability, increased vertical velocity (weaker subsidence/ stronger ascent, blue) should coincide with increased convection (red) and decreased static stability (blue).

Positive IMI anomalies in CCSM3 are associated with increased low-level vertical velocity (i.e., negative $\omega$ anomalies, ascent) in central India, over the west coast of the Indian peninsula, some parts of the Arabian Sea, and the Bay of Bengal, and increased mid and upperlevel vertical velocity over most parts of India, the Arabian Sea, and the Bay of Bengal, except for a small region in northeast India (Fig. 2c). It is important to note that these mid- and upper-level vertical velocity patterns resemble precipitation patterns associated with IMI anomalies (Fig. 2b), confirming that strengthened rising motion coincides with increased precipitation (e.g., Riehl and Malkus 1958). Similar conclusions regarding IMI-related vertical velocity patterns and precipitation patterns apply to the CGCM3.1 (T63) and CNRM-CM3 simulations, though the patterns differ in their details (Figs. 3c and 4c). Despite the increased low- and midlevel dry static stability over certain regions over South Asia described in section 4b.1 (Figs. 2a, 3a, and 4a), the increased mid- and upper-level upward motion over most parts of the South Asia associated with positive IMI anomalies further confirms that, on interannual time scales, the latent heating plays the predominant role over the dry static stability to determine the strength of the SASM circulation.

The low- and midtropospheric vertical velocity patterns for GISS-ER depict a distinct zonally oriented reversal of the vertical motion tendency around $10^{\circ} \mathrm{N}$ with negative anomalies to the north and positive anomalies to the south, indicating the intensified rising motions over the Indian subcontinent, the Arabian Sea, and the Bay of Bengal, and the strengthened subsidence in the North Indian Ocean in accordance with increased monsoon circulation (not shown). This broadly zonal pattern is very similar to the spatial pattern of the precipitation tendency at these latitudes (not shown). Although the separation between the positive and negative anomalies in GISS-EH is not as clearly defined as that shown in GISS-ER, we could still distinguish strong ascending motion anomalies north of $10^{\circ} \mathrm{N}$ and weak subsidence anomalies over the North Indian Ocean (Fig. 5c). The patterns for MIROC3.2(hires) are to some extent similar to that in these two GISS models, with upward motion anomalies over most parts of Indian, the Arabian Sea, and the Bay of Bengal, and subsidence anomalies over east and west equatorial Indian Ocean (Fig. 6c).

\section{c. Thermodynamic energy budget over South Asia}

For the purpose of quantitatively evaluating the thermodynamic energy budget of the SASM, we calculated the mean and changes in different terms in the thermodynamic energy equation during the summer monsoon season (JJA; Tables 3-5) averaged over part of the South Asian region $\left(10^{\circ}-20^{\circ} \mathrm{N}, 60^{\circ}-90^{\circ} \mathrm{E}\right)$; this region 
TABLE 3. The means of different terms in the thermodynamic energy equation applied to the NCEP-NCAR reanalysis and seven CMIP3 historical $(20 \mathrm{C} 3 \mathrm{M})$ simulations during the second half of the twentieth century. Spatial averages are computed over part of the South Asian region of $10^{\circ}-20^{\circ} \mathrm{N}, 60^{\circ}-90^{\circ} \mathrm{E}$. Shown are results for lower $(850 \mathrm{hPa})$, middle $(500 \mathrm{hPa})$, and upper $(300 \mathrm{hPa})$ atmospheric pressure levels, and the average over all three levels (in boldface).

\begin{tabular}{|c|c|c|c|c|}
\hline Models/observations & Pressure levels & $u \frac{\overline{\partial T}}{\partial x}+v \frac{\overline{\partial T}}{\partial y} \times 10^{-6} \mathrm{~K} \mathrm{~s}^{-1}$ & $-\overline{S_{p} \omega} \times 10^{-6} \mathrm{~K} \mathrm{~s}^{-1}$ & $\left(\overline{Q_{c}} / \rho h c_{p}\right) \times 10^{-6} \mathrm{~K} \mathrm{~s}^{-1}$ \\
\hline \multirow[t]{4}{*}{ NCEP-NCAR reanalysis (1948-2000) } & $850 \mathrm{hPa}$ & -9.194 & 14.74 & 25.41 \\
\hline & $500 \mathrm{hPa}$ & -0.448 & 25.22 & 39.81 \\
\hline & $300 \mathrm{hPa}$ & -2.789 & 33.60 & 60.36 \\
\hline & Mean & -4.144 & 24.52 & 41.86 \\
\hline \multirow[t]{4}{*}{ CCSM run1 (1948-99) } & $850 \mathrm{hPa}$ & & 18.41 & 20.58 \\
\hline & $500 \mathrm{hPa}$ & & 18.26 & 32.39 \\
\hline & $300 \mathrm{hPa}$ & & 17.18 & 48.94 \\
\hline & Mean & & 17.95 & 33.97 \\
\hline \multirow[t]{4}{*}{ CGCM3.1 (T63) run1 (1948-2000) } & $850 \mathrm{hPa}$ & & 18.94 & 22.60 \\
\hline & $500 \mathrm{hPa}$ & & 21.77 & 35.36 \\
\hline & $300 \mathrm{hPa}$ & & 16.74 & 53.23 \\
\hline & Mean & & 19.15 & 37.07 \\
\hline \multirow[t]{4}{*}{ CNRM-CM3 run1 (1948-99) } & $850 \mathrm{hPa}$ & & 16.22 & 23.56 \\
\hline & $500 \mathrm{hPa}$ & & 18.87 & 36.93 \\
\hline & $300 \mathrm{hPa}$ & & 26.24 & 55.57 \\
\hline & Mean & & 20.44 & 38.69 \\
\hline \multirow[t]{4}{*}{ GISS-EH run1 (1948-99) } & $850 \mathrm{hPa}$ & & 2.157 & 16.95 \\
\hline & $500 \mathrm{hPa}$ & & 11.28 & 26.53 \\
\hline & $300 \mathrm{hPa}$ & & 18.07 & 40.03 \\
\hline & Mean & & 10.50 & 27.84 \\
\hline \multirow[t]{4}{*}{ GISS-ER run2 (1948-2000) } & $850 \mathrm{hPa}$ & & 7.162 & 19.91 \\
\hline & $500 \mathrm{hPa}$ & & 9.246 & 31.17 \\
\hline & $300 \mathrm{hPa}$ & & 11.97 & 47.03 \\
\hline & Mean & & 9.460 & 32.70 \\
\hline \multirow[t]{4}{*}{ MIROC3.2(hires) run1 (1948-2000) } & $850 \mathrm{hPa}$ & & 12.08 & 27.01 \\
\hline & $500 \mathrm{hPa}$ & & 30.24 & 42.18 \\
\hline & $300 \mathrm{hPa}$ & & 32.63 & 63.86 \\
\hline & Mean & & 24.98 & 44.35 \\
\hline \multirow[t]{4}{*}{ MIROC3.2(medres) run1 (1948-2000) } & $850 \mathrm{hPa}$ & & 14.71 & 28.87 \\
\hline & $500 \mathrm{hPa}$ & & 34.53 & 45.12 \\
\hline & $300 \mathrm{hPa}$ & & 34.28 & 68.12 \\
\hline & Mean & & 27.84 & 47.37 \\
\hline
\end{tabular}

includes the southern Indian subcontinent, southeastern Arabian Sea, and the southwestern Bay of Bengal (Fig. 2b).

We first applied this thermodynamic energy budget analysis to the NCEP-NCAR reanalysis during the latter half of the twentieth century, and then compared the results with that from the seven CMIP historical (20C3M) simulations depicted in Figs. 2-6 over the same time interval as the reanalysis (Table 3 and 4). The convective heating term $\left(\overline{Q_{c}} / \rho h c_{p}\right)$ and adiabatic cooling term $\left(-\overline{S_{p} \omega}\right)$ have the same order of magnitude in these model simulations as in the reanalysis, though underestimated in GISS model realizations.

In the NCEP-NCAR reanalysis, the changes in different terms (i.e., changes in horizontal temperature advection term, two adiabatic terms, convective heating term, and radiative cooling term) averaged over three tropospheric pressure levels exhibit a reasonably good balance. Though the changes in each term are quite different in the seven simulations compared to that in NCEP-NCAR reanalysis in terms of both sign and magnitude, they come to balance in different ways (Table 4). It is important to note that since the daily data is not available over the continuous time intervals applied for this study in 20C3M and SRES A1B simulations (e.g., the daily data are only available over separated time slots in SRES A1B scenario such as 2046-65, 2081-2100, etc.), the horizontal advection terms cannot be calculated directly from the daily data of temperature and horizontal wind in the model simulations. Even without considering the horizontal temperature advection term, however, the changes in other terms in the NCEPNCAR reanalysis still reach a fairly good balance. Therefore, we estimated changes in the temperature advection 
TABLE 4. Changes in different terms in the thermodynamic energy equation applied to the NCEP-NCAR reanalysis and seven CMIP3 historical (20C3M) simulations during the second half of the twentieth century. Spatial averages are computed over part of the South Asian region of $10^{\circ}-20^{\circ} \mathrm{N}, 60^{\circ}-90^{\circ} \mathrm{E}$. Changes are calculated based on the difference between the means over the last and first $10 \mathrm{yr}$. The average over all three levels are in boldface.

\begin{tabular}{|c|c|c|c|c|c|c|}
\hline \multirow[b]{2}{*}{ Models/observations } & \multirow[b]{2}{*}{$\begin{array}{c}\text { Pressure } \\
\text { levels }\end{array}$} & \multirow{2}{*}{$\delta\left(u \frac{\overline{\partial T}}{\partial x}+v \frac{\overline{\partial T}}{\partial y}\right) \times$} & \multirow[b]{2}{*}{$\begin{array}{c}-\overline{S_{p}} \delta \bar{\omega} \times \\
10^{-b} \mathrm{~K} \mathrm{~s}^{-1}\end{array}$} & \multirow[b]{2}{*}{$\begin{array}{c}-\bar{\omega} \delta \overline{S_{p}} \times \\
10^{-6} \mathrm{~K} \mathrm{~s}^{-1}\end{array}$} & \multirow[b]{2}{*}{$\begin{array}{c}\delta\left(\overline{Q_{c}} / \rho h c_{p}\right) \times \\
10^{-6} \mathrm{~K} \mathrm{~s}^{-1}\end{array}$} & $-\gamma \delta \bar{T}$ \\
\hline & & & & & & $\begin{array}{c}\gamma=1 / 30(1 / 40 \sim \\
1 / 20) \times 10^{-6} \mathrm{~K} \mathrm{~s}^{-1}\end{array}$ \\
\hline \multirow{4}{*}{$\begin{array}{l}\text { NCEP-NCAR } \\
\text { reanalysis }(1948-2000)\end{array}$} & $850 \mathrm{hPa}$ & 1.074 & -0.215 & -0.430 & -3.662 & $-0.330(-0.25 \sim-0.50)$ \\
\hline & $500 \mathrm{hPa}$ & 0.914 & -7.125 & -0.526 & -5.758 & $-0.254(-0.19 \sim-0.38)$ \\
\hline & $300 \mathrm{hPa}$ & 1.609 & -14.77 & -1.162 & -8.812 & $-0.105(-0.08 \sim-0.16)$ \\
\hline & Mean & 1.199 & -7.370 & -0.706 & -6.077 & $-0.230(-0.17 \sim-0.34)$ \\
\hline \multirow{4}{*}{$\begin{array}{r}\text { CCSM run1 } \\
(1948-99)\end{array}$} & $850 \mathrm{hPa}$ & $-0.443(-0.41 \sim-0.50)$ & -0.569 & 0.480 & -0.420 & $-0.112(-0.08 \sim-0.17)$ \\
\hline & $500 \mathrm{hPa}$ & $0.504(0.53 \sim 0.43)$ & -1.290 & 0.003 & -0.643 & $-0.140(-0.11 \sim-0.21)$ \\
\hline & $300 \mathrm{hPa}$ & $-1.666(-1.62 \sim-1.77)$ & 0.061 & 0.474 & -0.933 & $-0.200(-0.15 \sim-0.30)$ \\
\hline & Mean & $-0.536(-0.50 \sim-0.62)$ & -0.599 & 0.319 & -0.665 & $-0.151(-0.11 \sim-0.23)$ \\
\hline \multirow{4}{*}{$\begin{array}{l}\text { CGCM3.1 (T63) run1 } \\
\quad(1948-2000)\end{array}$} & $850 \mathrm{hPa}$ & $0.633(0.74 \sim 0.44)$ & -0.901 & 0.402 & 0.536 & $-0.402(-0.30 \sim-0.60)$ \\
\hline & $500 \mathrm{hPa}$ & $0.482(0.61 \sim 0.22)$ & -1.225 & 1.092 & 0.879 & $-0.530(-0.40 \sim-0.79)$ \\
\hline & $300 \mathrm{hPa}$ & $0.123(0.31 \sim-0.25)$ & -0.513 & 1.128 & 1.484 & $-0.746(-0.56 \sim-1.12)$ \\
\hline & Mean & $0.413(0.55 \sim 0.13)$ & -0.880 & 0.874 & 0.966 & $-0.559(-0.42 \sim-0.84)$ \\
\hline \multirow{4}{*}{$\begin{array}{l}\text { CNRM-CM3 run1 } \\
\quad(1948-99)\end{array}$} & $850 \mathrm{hPa}$ & $-0.573(-0.50 \sim-0.72)$ & 1.316 & 0.197 & 1.242 & $-0.302(-0.23 \sim-0.45)$ \\
\hline & $500 \mathrm{hPa}$ & $1.123(1.21 \sim 0.93)$ & -0.099 & 0.584 & 1.988 & $-0.380(-0.29 \sim-0.57)$ \\
\hline & $300 \mathrm{hPa}$ & $0.141(0.29 \sim-0.15)$ & 0.100 & 2.310 & 3.137 & $-0.586(-0.44 \sim-0.88)$ \\
\hline & Mean & $0.230(0.33 \sim 0.02)$ & 0.439 & 1.030 & 2.122 & $-0.423(-0.32 \sim-0.63)$ \\
\hline \multirow{4}{*}{$\begin{array}{l}\text { GISS-EH run1 } \\
(1948-99)\end{array}$} & $850 \mathrm{hPa}$ & $-0.369(-0.34 \sim-0.43)$ & -0.195 & 0.028 & -0.409 & $-0.127(-0.10 \sim-0.19)$ \\
\hline & $500 \mathrm{hPa}$ & $-0.076(-0.03 \sim-0.17)$ & -0.787 & 0.064 & -0.620 & $-0.179(-0.13 \sim-0.27)$ \\
\hline & $300 \mathrm{hPa}$ & $0.426(0.47 \sim 0.33)$ & -1.702 & 0.163 & -0.926 & $-0.187(-0.14 \sim-0.28)$ \\
\hline & Mean & $-0.007(0.04 \sim-0.09)$ & -0.895 & 0.085 & -0.652 & $-0.165(-0.12 \sim-0.25)$ \\
\hline \multirow{4}{*}{$\begin{array}{r}\text { GISS-ER run2 } \\
(1948-2000)\end{array}$} & $850 \mathrm{hPa}$ & $-0.747(-0.73 \sim-0.77)$ & 0.851 & 0.116 & 0.275 & $-0.055(-0.04 \sim-0.08)$ \\
\hline & $500 \mathrm{hPa}$ & $-0.841(-0.80 \sim-0.92)$ & 0.903 & 0.226 & 0.450 & $-0.162(-0.12 \sim-0.24)$ \\
\hline & $300 \mathrm{hPa}$ & $-0.533(-0.48 \sim-0.65)$ & 0.820 & 0.198 & 0.720 & $-0.235(-0.18 \sim-0.35)$ \\
\hline & Mean & $-0.707(-0.67 \sim-0.79)$ & 0.858 & 0.180 & 0.482 & $-0.151(-0.11 \sim-0.23)$ \\
\hline \multirow{4}{*}{$\begin{array}{l}\text { MIROC3.2(hires) run1 } \\
\quad(1948-2000)\end{array}$} & $850 \mathrm{hPa}$ & $1.022(1.05 \sim 0.97)$ & 1.455 & 0.309 & 2.903 & $-0.117(-0.09 \sim-0.17)$ \\
\hline & $500 \mathrm{hPa}$ & $-0.369(-0.32 \sim-0.48)$ & 3.914 & 0.835 & 4.593 & $-0.213(-0.16 \sim-0.32)$ \\
\hline & $300 \mathrm{hPa}$ & $0.005(0.08 \sim-0.14)$ & 5.802 & 0.928 & 7.028 & $-0.293(-0.22 \sim-0.44)$ \\
\hline & Mean & $0.218(0.27 \sim 0.12)$ & 3.724 & 0.691 & 4.841 & $-0.208(-0.16 \sim-0.31)$ \\
\hline \multirow{4}{*}{$\begin{array}{l}\text { MIROC3.2(medres) run1 } \\
\quad(1948-2000)\end{array}$} & $850 \mathrm{hPa}$ & $0.878(0.91 \sim 0.82)$ & 0.162 & -0.103 & 1.049 & $-0.112(-0.08 \sim-0.17)$ \\
\hline & $500 \mathrm{hPa}$ & $0.093(0.11 \sim 0.06)$ & 1.737 & -0.276 & 1.628 & $-0.074(-0.06 \sim-0.11)$ \\
\hline & $300 \mathrm{hPa}$ & $-1.154(-1.13 \sim-1.19)$ & 2.704 & 0.839 & 2.462 & $-0.073(-0.05 \sim-0.11)$ \\
\hline & Mean & $-0.061(-0.04 \sim-0.11)$ & 1.534 & 0.154 & 1.713 & $-0.086(-0.06 \sim-0.13)$ \\
\hline
\end{tabular}

terms for each of these seven SRES A1B simulations as a residual of the other terms calculated directly from these simulations.

In SRES A1B scenario, all seven simulations from the seven selected models show the increased dry static stability during the last $10 \mathrm{yr}$ compared to the first $10 \mathrm{yr}$ of the twenty-first century (Table 5). For the six simulations indicating significant decreasing trend of the IMI, all but one case [MIROC3.2(medres)] exhibit decreased upward motion over this region. It is worth asking whether the convective heating term $\left[\delta\left(\overline{Q_{c}} / \rho h c_{p}\right)\right]$ decreases or increases by a relatively small amount compared to the increased adiabatic term $\left(-\bar{\omega} \delta \overline{S_{p}}\right)$ in these five simulations in accordance with decreased upward motion (i.e., decreased adiabatic term $-\overline{S_{p}} \delta \bar{\omega}$ ). Indeed, two of the simulations (CCSM3 and GISS-ER) indicate a decreased convective heating term, which means that the decreased convective heating and the increased dry static stability work together in consistency with the decreased rising motion. Though the convective heating term has also increased in the other two of these five simulations [CNRM-CM3 and MIROC3.2(hires)], the increasing magnitude is smaller than that of the adiabatic term $-\bar{\omega} \delta \overline{S_{p}}$ [e.g., the increase of the convective heating term averaged over three pressure levels is about $53 \%$ and $70 \%$ of that of the adiabatic ascent/subsidence term $-\bar{\omega} \delta \overline{S_{p}}$ in CNRM-CM3 and MIROC3.2(hires), respectively], indicating that the effect of dry static stability wins over the effect of the convective heating in accordance with the weakening of the ascending motion and the monsoon circulation.

One exception is a realization of GISS-EH showing that, in spite of a greater increase in convective heating $\delta\left(\overline{Q_{c}} / \rho h c_{p}\right)\left(1.099 \times 10^{-6} \mathrm{~K} \mathrm{~s}^{-1}\right)$ than the increase in 
TABLE 5. Changes in different terms in the thermodynamic energy equation applied to the seven CMIP3 simulations of Table 3 but for the twenty-first century A1B emission scenario. Spatial averages are computed over part of the South Asian region of $10^{\circ}-20^{\circ} \mathrm{N}, 60^{\circ}-90^{\circ} \mathrm{E}$. Changes are calculated based on the difference between the means over the last and first $10 \mathrm{yr}$ of the twenty-first century. The average over all three levels are in boldface.

\begin{tabular}{|c|c|c|c|c|c|c|}
\hline Models & $\begin{array}{c}\text { Pressure } \\
\text { levels }\end{array}$ & $\begin{array}{c}\delta\left(u \frac{\overline{\partial T}}{\partial x}+v \frac{\overline{\partial T}}{\partial y}\right) \times \\
10^{-6} \mathrm{~K} \mathrm{~s}^{-1}\end{array}$ & $\begin{array}{l}-\overline{S_{p}} \delta \bar{\omega} \times \\
10^{-6} \mathrm{~K} \mathrm{~s}^{-1}\end{array}$ & $\begin{array}{c}-\bar{\omega} \delta \overline{S_{p}} \times \\
10^{-6} \mathrm{~K} \mathrm{~s}^{-1}\end{array}$ & $\begin{array}{c}\overline{Q_{c}} / \rho h c_{p} \times \\
10^{-6} \mathrm{~K}^{-1}{ }^{-1}\end{array}$ & $\begin{array}{c}-\gamma \delta \bar{T} \\
\gamma=1 / 30(1 / 40 \sim 1 / 20) \times \\
10^{-6} \mathrm{~K} \mathrm{~s}^{-1}\end{array}$ \\
\hline \multirow[t]{4}{*}{ CCSM3 run1 (2000-99) } & $850 \mathrm{hPa}$ & $-1.064(-0.88 \sim-1.44)$ & -0.558 & 0.581 & -0.294 & $-0.747(-0.56 \sim-1.12)$ \\
\hline & $500 \mathrm{hPa}$ & $1.732(1.94 \sim 1.33)$ & -3.899 & 0.924 & -0.439 & $-0.804(-0.60 \sim-1.21)$ \\
\hline & $300 \mathrm{hPa}$ & $0.768(1.13 \sim 0.05)$ & -5.080 & 2.639 & -0.235 & $-1.438(-1.08 \sim-2.16)$ \\
\hline & Mean & $0.478(0.73 \sim-0.02)$ & -3.179 & 1.381 & -0.323 & $-0.997(-0.75 \sim-1.49)$ \\
\hline \multirow{4}{*}{$\begin{array}{l}\text { CGCM3.1 (T63) run1 } \\
\quad(2001-2100)\end{array}$} & $850 \mathrm{hPa}$ & $1.555(1.75 \sim 1.18)$ & 0.962 & 1.093 & 4.370 & $-0.760(-0.57 \sim-1.14)$ \\
\hline & $500 \mathrm{hPa}$ & $0.340(0.67 \sim-0.34)$ & 2.838 & 2.585 & 7.107 & $-1.344(-1.01 \sim-2.02)$ \\
\hline & $300 \mathrm{hPa}$ & $0.332(0.81 \sim-0.63)$ & 4.747 & 4.230 & 11.22 & $-1.911(-1.43 \sim-2.87)$ \\
\hline & Mean & $0.743(1.08 \sim 0.07)$ & 2.849 & 2.636 & 7.566 & $-1.338(-1.00 \sim-2.01)$ \\
\hline \multirow{4}{*}{$\begin{array}{l}\text { CNRM-CM3 run1 } \\
(2000-2100)\end{array}$} & $850 \mathrm{hPa}$ & $-1.494(-1.24 \sim-2.01)$ & 0.487 & 0.690 & 0.711 & $-1.028(-0.77 \sim-1.54)$ \\
\hline & $500 \mathrm{hPa}$ & $1.689(1.97 \sim 1.12)$ & -2.881 & 1.255 & 1.197 & $-1.134(-0.85 \sim-1.70)$ \\
\hline & $300 \mathrm{hPa}$ & $1.041(1.46 \sim 0.21)$ & -6.290 & 5.796 & 2.212 & $-1.665(-1.25 \sim-2.50)$ \\
\hline & Mean & $0.413(0.73 \sim-0.22)$ & -2.895 & 2.580 & 1.373 & $-1.275(-0.96 \sim-1.91)$ \\
\hline \multirow[t]{4}{*}{ GISS-EH run1 (2000-99) } & $850 \mathrm{hPa}$ & $1.436(1.67 \sim 0.97)$ & -1.884 & 0.098 & 0.584 & $-0.934(-0.70 \sim-1.40)$ \\
\hline & $500 \mathrm{hPa}$ & $2.426(2.69 \sim 1.90)$ & -3.136 & 0.646 & 0.998 & $-1.062(-0.80 \sim-1.59)$ \\
\hline & $300 \mathrm{hPa}$ & $3.282(3.64 \sim 2.58)$ & -4.897 & 1.915 & 1.713 & $-1.413(-1.06 \sim-2.12)$ \\
\hline & Mean & $2.383(2.67 \sim 1.82)$ & -3.306 & 0.886 & 1.099 & $-1.136(-0.85 \sim-1.70)$ \\
\hline \multirow{4}{*}{$\begin{array}{c}\text { GISS-ER run2 } \\
(2004-2100)\end{array}$} & $850 \mathrm{hPa}$ & $-0.005(0.21 \sim-0.42)$ & -2.098 & 0.384 & -0.877 & $-0.842(-0.63 \sim-1.26)$ \\
\hline & $500 \mathrm{hPa}$ & $2.049(2.30 \sim 1.55)$ & -4.796 & 0.467 & -1.283 & $-0.997(-0.75 \sim-1.50)$ \\
\hline & $300 \mathrm{hPa}$ & $1.701(2.02 \sim 1.05)$ & -5.856 & 1.130 & -1.733 & $-1.292(-0.97 \sim-1.94)$ \\
\hline & Mean & $1.248(1.51 \sim 0.72)$ & -4.250 & 0.660 & -1.298 & $-1.044(-0.78 \sim-1.57)$ \\
\hline \multirow{4}{*}{$\begin{array}{l}\text { MIROC3.2 (hires) } \\
\text { run1 (2001-2100) }\end{array}$} & $850 \mathrm{hPa}$ & $2.248(2.63 \sim 1.49)$ & -3.320 & 1.271 & 1.720 & $-1.521(-1.14 \sim-2.28)$ \\
\hline & $500 \mathrm{hPa}$ & $0.785(1.19 \sim-0.01)$ & -3.081 & 3.477 & 2.771 & $-1.590(-1.19 \sim-2.38)$ \\
\hline & $300 \mathrm{hPa}$ & $-5.899(-5.31 \sim-7.09)$ & -0.284 & 8.696 & 4.885 & $-2.372(-1.78 \sim-3.56)$ \\
\hline & Mean & $-0.956(-0.50 \sim-1.87)$ & -2.228 & 4.481 & 3.125 & $-1.828(-1.37 \sim-2.74)$ \\
\hline \multirow{4}{*}{$\begin{array}{l}\text { MIROC3.2 (medres) } \\
\text { run1 (2001-2100) }\end{array}$} & $850 \mathrm{hPa}$ & $2.816(3.11 \sim 2.21)$ & -0.466 & 1.526 & 5.084 & $-1.208(-0.91 \sim-1.81)$ \\
\hline & $500 \mathrm{hPa}$ & $-0.590(-0.30 \sim-1.19)$ & 3.229 & 4.179 & 8.003 & $-1.185(-0.89 \sim-1.78)$ \\
\hline & $300 \mathrm{hPa}$ & $-1.149(-0.61 \sim-2.24)$ & 3.203 & 8.814 & 13.04 & $-2.172(-1.63 \sim-3.26)$ \\
\hline & Mean & $0.359(0.74 \sim-0.40)$ & 1.989 & 4.840 & 8.710 & $-1.522(-1.14 \sim-2.28)$ \\
\hline
\end{tabular}

$-\bar{\omega} \delta \overline{S_{p}}\left(8.862 \times 10^{-7} \mathrm{~K} \mathrm{~s}^{-1}\right)$, the rising motion still decreases with the negative term $-\overline{S_{p}} \delta \bar{\omega}\left(-3.306 \times 10^{-6}\right.$ $\mathrm{K} \mathrm{s}^{-1}$ ). In the simulation from CGCM3.1 (T63), the only one showing strengthened SASM circulation among seven selected models, the magnitude of the increased convective heating $\delta\left(\overline{Q_{c}} / \rho h c_{p}\right)\left(7.566 \times 10^{-6} \mathrm{~K} \mathrm{~s}^{-1}\right)$ is more than 2.5 times the increase in $-\bar{\omega} \delta \overline{S_{p}}(2.636 \times$ $10^{-6} \mathrm{~K} \mathrm{~s}^{-1}$ ), implying that the impact of the convective heating overwhelms the influence of the increased dry static stability, consistent with the increased ascending motion and monsoon circulation.

Because of the uncertainty in the magnitude of the changes in the radiative cooling term (depending on the choice of $\gamma$ ), there is a corresponding range of the changes in the temperature advection term estimated as the residual in the model simulations. Within the range of $\gamma$ from $1 / 40$ to $1 / 20$, the changes in the temperature advection term calculated as the residual are consistently smaller than either of the changes in the two adiabatic terms in five of the seven simulations [i.e., CCSM3, CGCM3.1 (T63), CNRM-CM3,
MIROC3.2(hires), and MIROC3.2(medres)], or smaller than the changes in at least one of the two adiabatic terms in the other two simulations (i.e., GISS-EH and GISS-ER) in this SRES A1B scenario (Table 5). This thermodynamic energy budget analysis applied to SRES A1B simulations suggests that, in general, the SASM IMI trend can be interpreted as the common effects of an increase (a decrease) in convective heating and an increase in dry static stability. However, a caveat for this analysis is that the changes in horizontal temperature advection term may not be negligible depending on the choice of $\gamma$. Given future model outputs with daily data available, it will be possible to recalculate the horizontal temperature advection term precisely to refine our conclusions.

\section{d. SASM-ENSO relationship}

Given that ENSO is a crucial factor influencing yearto-year fluctuations in the SASM over the historical era, it is important to consider the projected changes in ENSO and their relationship with changes in the SASM. 
We examine these relationships for 44 simulations for which ENSO behavior was diagnosed. As in Fan et al. (2010), we defined ENSO by the zonal gradient of the boreal winter [December-February (DJF)] equatorial SST along $120^{\circ} \mathrm{E}-90^{\circ} \mathrm{W}$ ("niñograd"). This particular ENSO metric, unlike alternative measure such as Niño-3 or Niño-3.4, has the advantage of being insensitive to any uniform tropical warming, measuring instead the changes in east-west SST gradients across the equatorial Pacific most relevant to ENSO.

We first examined the issue of whether or not the observed weakening of the SASM-ENSO anticorrelation in recent decades continues on in model projections of the twenty-first-century behavior. As niñograd series in three runs of CCSM3 and one run of PCM was not analyzed in our former parallel analysis of $20 \mathrm{C} 3 \mathrm{M}$ simulations, the comparison is restricted to 40 simulations. We find in fact that there is no significant projected further weakening of the (inverse) relationship between the SASM and ENSO during the twenty-first century (Table 6), contrasting with the weakening trend seen in the second half of the twentieth century (see Table 1 in Fan et al. 2010). Indeed, $27.5 \%$ (11 out of 40 ) of the simulations even show a significant strengthening of the negative SASM-ENSO correlation [e.g., Bjerknes Center for Climate Research (BCCR) Bergen Climate Model version 2.0 (BCM2.0)], while $42.5 \%$ (17 out of 40 ) indicate a stable negative correlation (e.g., GFDL-CM2.0) or only a very slight strengthening [e.g., CSIRO Mark version 3.5 (Mk3.5]. This observation is consistent with the conclusion by Fan et al. (2010) that the observed weakening of the SASMENSO relationship in recent decades could potentially simply be a manifestation of internal multidecadal variability of the climate system. This finding is also consistent with the results from several earlier studies. Using a subset of the CMIP3 climate models (ECHAM5/MPI-OM, GFDL CM2.0, GFDL CM2.1, and MRI), Annamalai et al. (2007) concluded that the correlations between Indian monsoon precipitation and equatorial Pacific SST remain similar or even strengthened under $\mathrm{CO}_{2}$ doubling by comparison to the $20 \mathrm{C} 3 \mathrm{M}$ simulations. Ashrit et al. (2003) and Turner et al. (2007) also noted that the relationship between Niño-3 and the Webster and Yang Monsoon index remains robust in their transient climate change and doubling $\mathrm{CO}_{2}$ studies with one particular climate model.

We next reexamined the projected trends in ENSO mean state and their relationship with trends in SASM, by subclassifying the SASM trends with respect to whether the associated simulation projects a more El Niño-like or La Niña-like mean state (as judged by the trend in niñograd-see Fig. 7). We found the majority (30 out of 44) of A1B simulations to project a more
TABLE 6. Correlations between the SASM IMI and niñograd index during the twenty-first century for 23 models (44 realizations) for which ENSO behavior have been analyzed. Negative correlations that are statistically significant at the one-sided $p=0.05$ level $(p=0.1$ level) are shown in boldface (italics).

\begin{tabular}{|c|c|c|}
\hline Models & Runs & 2000/2001-2098/2099 \\
\hline BCCR-BCM2.0 & Run1 & -0.236 \\
\hline \multirow[t]{3}{*}{ CCSM3 } & Run2 & -0.156 \\
\hline & Run5 & 0.011 \\
\hline & Run6 & -0.067 \\
\hline \multirow[t]{5}{*}{ CGCM3.1 (T47) } & Run1 & -0.281 \\
\hline & Run2 & -0.219 \\
\hline & Run3 & -0.267 \\
\hline & Run4 & -0.146 \\
\hline & Run5 & -0.191 \\
\hline CGCM3.1 (T63) & Run1 & -0.080 \\
\hline CNRM-CM3 & Run1 & -0.189 \\
\hline CSIRO Mk3.0 & Run1 & -0.168 \\
\hline CSIRO Mk3.5 & Run1 & -0.369 \\
\hline \multirow[t]{2}{*}{ ECHAM5/MPI-OM } & Run1 & -0.359 \\
\hline & Run2 & -0.555 \\
\hline \multirow[t]{3}{*}{ FGOALS-g1.0 } & Run1 & -0.192 \\
\hline & Run2 & -0.209 \\
\hline & Run3 & -0.242 \\
\hline GFDL CM2.0 & Run1 & -0.325 \\
\hline GFDL CM2.1 & Run1 & -0.441 \\
\hline \multirow{2}{*}{ GISS-AOM } & Run1 & 0.012 \\
\hline & Run2 & -0.082 \\
\hline \multirow[t]{3}{*}{ GISS-EH } & Run1 & -0.060 \\
\hline & Run2 & -0.098 \\
\hline & Run3 & 0.032 \\
\hline \multirow[t]{2}{*}{ GISS-ER } & Run2 & 0.288 \\
\hline & Run4 & 0.417 \\
\hline INGV-SXG & Run1 & -0.338 \\
\hline INM-CM3.0 & Run1 & -0.011 \\
\hline IPSL CM4 & Run1 & -0.179 \\
\hline MIROC3.2(hires) & Run1 & -0.225 \\
\hline \multirow[t]{3}{*}{ MIROC3.2(medres) } & Run1 & -0.095 \\
\hline & Run2 & -0.394 \\
\hline & Run3 & -0.197 \\
\hline \multirow[t]{5}{*}{ MRI-CGCM2.3.2 } & Run1 & -0.605 \\
\hline & Run2 & -0.572 \\
\hline & Run3 & -0.490 \\
\hline & Run4 & -0.632 \\
\hline & Run5 & -0.575 \\
\hline \multirow[t]{3}{*}{ PCM } & Run2 & -0.284 \\
\hline & Run3 & -0.220 \\
\hline & Run4 & -0.446 \\
\hline UKMO HadCM3 & Run1 & -0.110 \\
\hline UKMO HadGEM1 & Run1 & 0.096 \\
\hline
\end{tabular}

El Niño-like mean state in response to increased greenhouse gas concentrations. However, these El Niñotrending models did not indicate a greater tendency for a weakening SASM circulation than the La Niña-trending models. The percentage of simulations associated with a weakened SASM (i.e., negative trend in IMI) are nearly equal among El Niño-trending and La Niña-trending simulations [76.7\% (23 out of 30 ) and $71.4 \%$ (10 out of 

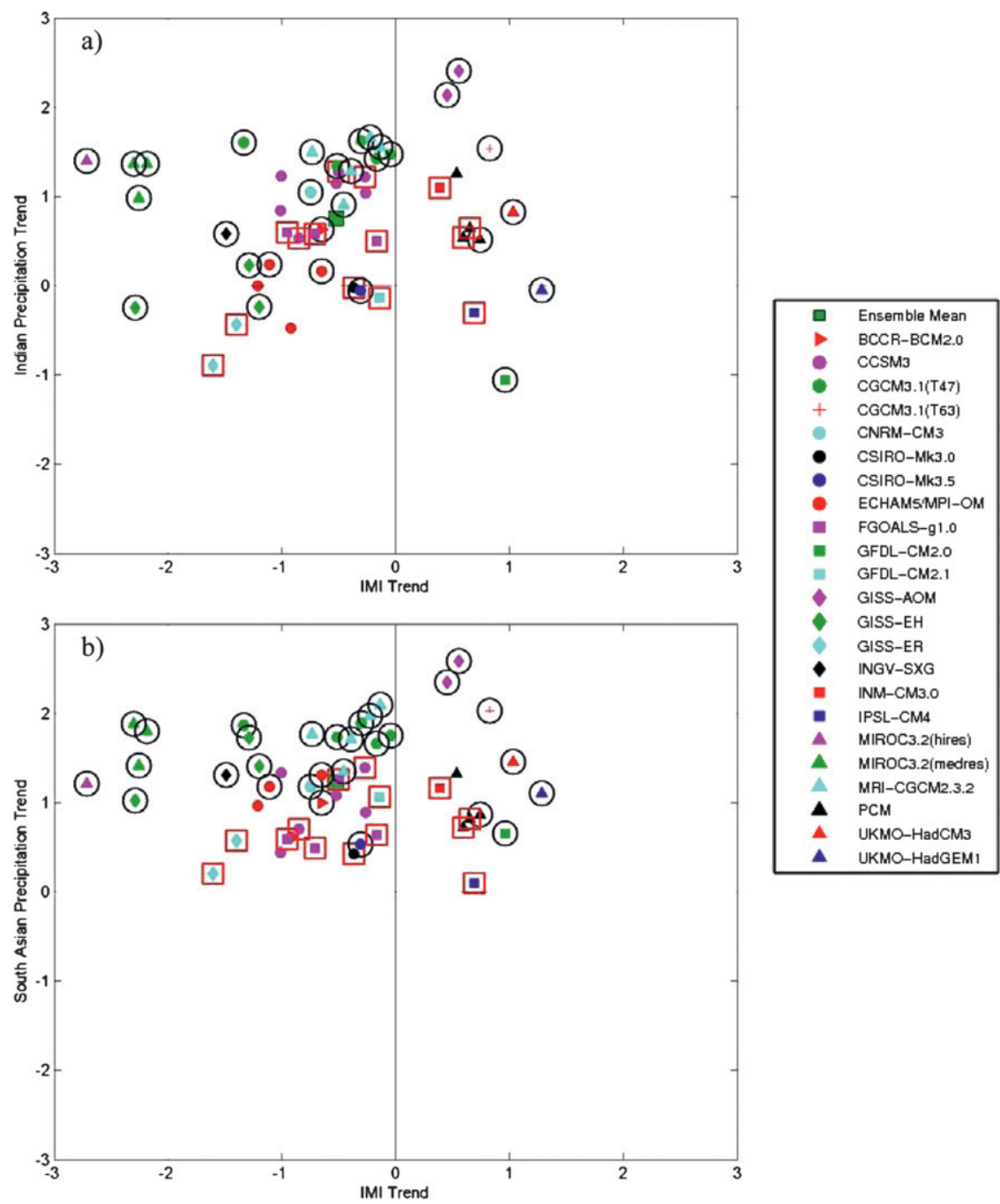

FIG. 7. Trends in the SASM circulation and precipitation as in (a) Fig. $1 \mathrm{~b}$ and (b) Fig. 1d, but distinguishing models that project a more El Niño-like mean state (black circles) from those that project a more La Niña-like mean state (red squares) for the 23 models (44 realizations) for which ENSO mean state changes have been diagnosed.

14), respectively.] On the other hand, a majority of the 15 models that best capture the observed interannual relationship between ENSO and the SASM (i.e., which exhibit significant anticorrelation between the IMI and niñograd at interannual time scales) project changes in SASM consistent with the projected changes in ENSO. Eleven of these 15 models display El Niño-trending (La Niña-trending) simulations behavior in association with weakened (strengthened) SASM circulation. Thus, in those models that appear to capture the observed ENSO-SASM relationship most faithfully, changes in ENSO do appear to be playing some role in the projected changes in the SASM circulation.

\section{Conclusions}

Simulations of the SASM in a set of coupled AOGCMs show a clear tendency for both a weakening SASM circulation and increasing SASM precipitation in the projected response to twenty-first century anthropogenic greenhouse gas emissions. Trends are far more consistent for the projected behavior over the twentyfirst century than they are for the retrospective historical simulations analyzed in previous work (Fan et al. 2010).

We find that two competing factors on monsoonal circulation (i.e., convective latent heating and dry static stability) appear to vary in prominence on different time scales. Regressing an index of monsoonal circulation 
(IMI) onto atmospheric fields, and focusing on seven representative models, we find that, on interannual time scales, all but one model [MIROC3.2(medres)] displays intensified midtropospheric latent heating and increased low- and midlevel dry static stability over India and surrounding oceanic regions in conjunction with a stronger SASM circulation (the detailed regional patterns are model dependent). These observations indicate that convective heating dominates over impacts of dry static stability. As regions of increased precipitation generally correspond to regions of increased low-level dry static stability with positive IMI anomalies, we may ascribe this increase in the dry static stability to the extra midtropospheric latent heat release.

On longer time scales, we find evidence for a different balance among terms in the thermodynamic energy equation. In all but one case (GISS-EH), we observe an approximate balance between the contributions of dry static stability, convective heating, and vertical velocity. Irrespective of trends in the convective heating, we observe an increase in dry static stability in all seven model simulations. This leaves two possibilities: 1) the increase in convective heating is greater (smaller) than the increase in adiabatic ascent (subsidence) to affect changes in dry static stability in accordance with a strengthened (weakened) monsoonal circulation, or 2) the convective heating decreases accompanied by the increased dry static stability for the further decrease in monsoonal circulation strength.

Our findings with regard to projected trends in SASM circulation and precipitation are generally consistent with conclusions from a number of previous studies of the response of the SASM to anthropogenic greenhouse forcing. We observe that while increased SASM precipitation accompanies a strengthened SASM circulation on interannual time scales, there is an apparent decoupling of the long-term monsoon precipitation and circulation trends. This decoupling is associated with distinct changes in moisture and mass convergence that take place in an increasingly warmer atmosphere with enhanced moisture content. Projected changes in ENSO also appear to be playing some role in the projected changes in SASM circulation, particularly in those models that best capture the observed interannual relationship between the two phenomena.

Acknowledgments. We thank Sonya Miller for assistance in calculating ENSO diagnostics from the climate model simulations. We acknowledge the climate modeling groups, the Program for Climate Model Diagnosis and Intercomparison (PCMDI), and the World Climate Research Programme's (WCRP's) Working Group on
Coupled Modeling (WGCM) for their roles in making available the "WCRP CMIP3 multi-model dataset." Support of this dataset is provided by the Office of Science, U.S. Department of Energy.

\section{REFERENCES}

Annamalai, H., K. Hamilton, and K. R. Sperber, 2007: The South Asian summer monsoon and its relationship with ENSO in the IPCC AR4 simulations. J. Climate, 20, 1071-1092.

Ashrit, R. G., H. Douville, and K. Rupa Kumar, 2003: Response of the Indian monsoon and ENSO-monsoon teleconnection to enhanced greenhouse effect in the CNRM coupled model. J. Meteor. Soc. Japan, 81, 779-803.

Bhaskaran, B., J. F. B. Mitchell, J. R. Lavery, and M. Lal, 1995: Climatic response of the Indian subcontinent to doubled $\mathrm{CO}_{2}$ concentrations. Int. J. Climatol., 15, 873-892.

Dairaku, K., and S. Emori, 2006: Dynamic and thermodynamic influences on intensified daily rainfall during the Asian summer monsoon under doubled atmospheric $\mathrm{CO}_{2}$ conditions. Geophys. Res. Lett., 33, L01704, doi:10.1029/2005GL024754.

Douville, H., J.-F. Royer, J. Polcher, P. Cox, N. Gedney, D. B. Stephenson, and P. J. Valdes, 2000: Impact of $\mathrm{CO}_{2}$ doubling on the Asian summer monsoon: Robust versus model-dependent responses. J. Meteor. Soc. Japan, 78, 421-439.

Fan, F., M. E. Mann, and C. M. Ammann, 2009: Understanding changes in the Asian summer monsoon over the past millennium: Insights from a long-term coupled model simulation. J. Climate, 22, 1736-1748.

, - - S. Lee, and J. L. Evans, 2010: Observed and modeled changes in the South Asian summer monsoon over the historical period. J. Climate, 23, 5193-5205.

Goswami, B. N., V. Krishnamurthy, and H. Annamalai, 1999: A broad-scale circulation index for the interannual variability of the Indian summer monsoon. Quart. J. Roy. Meteor. Soc., 125, 611-633.

Houghton, J. T., Y. Ding, D. J. Griggs, M. Noguer, P. J. van der Linden, X. Dai, K. Maskell, and C. A. Johnson, Eds., 2001: Climate Change 2001: The Scientific Basis. Cambridge University Press, $881 \mathrm{pp}$.

Hu, Z. Z., M. Latif, E. Roeckner, and L. Bengtsson, 2000: Intensified Asian summer monsoon and its variability in a coupled model forced by increasing greenhouse gas concentrations. Geophys. Res. Lett., 27, 2681-2684.

Kitoh, A., S. Yukimoto, A. Noda, and T. Motoi, 1997: Simulated changes in the Asian summer monsoon at times of increased atmospheric $\mathrm{CO}_{2}$. J. Meteor. Soc. Japan, 75, 1019-1031.

Krishna Kumar, K., and Coauthors, 2011: The once and future pulse of Indian monsoonal climate. Climate Dyn., 36, 2159 2170.

Lal, M., G. A. Meehl, and J. M. Arblaster, 2000: Simulation of Indian summer monsoon rainfall and its intraseasonal variability in the NCAR climate system model. Reg. Environ. Change, 1, 163-179.

May, W., 2002: Simulated changes of the Indian summer monsoon under enhanced greenhouse gas conditions in a global timeslice experiment. Geophys. Res. Lett., 29, 1118, doi:10.1029/ 2001 GL013808.

, 2004: Potential future changes in the Indian summer monsoon due to greenhouse warming: Analysis of mechanisms in a global time-slice experiment. Climate Dyn., 22, 389414. 
Meehl, G. A., and W. M. Washington, 1993: South Asian summer monsoon variability in a model with doubled atmospheric carbon dioxide concentration. Science, 260, 1101-1104.

— changes in South Asian monsoon precipitation. Climate Dyn., 21, 659-675.

— , and Coauthors, 2007: Global climate projections. Climate Change 2007: The Physical Science Basis, S. Solomon et al., Eds., Cambridge University Press, 747-845.

Nakićenović, N., and Coauthors, 2000: Emission Scenarios. Cambridge University Press, 599 pp.

Parthasarathy, B., K. Rupa Kumar, and D. R. Kothawale, 1992: Indian summer monsoon rainfall indices: 1871-1990. Meteor. Mag., 121, 174-186.

— A. A. Munot, and D. R. Kothawale, 1994: All-India monthly and seasonal rainfall series: 1871-1993. Theor. Appl. Climatol., 49, 217-224.
Riehl, H., and J. S. Malkus, 1958: On the heat balance in the equatorial trough zone. Geophysica, 6, 503-537.

Turner, A. G., P. M. Inness, and J. M. Slingo, 2007: The effect of doubled $\mathrm{CO}_{2}$ and model basic state biases on the monsoonENSO system. I: Mean response and interannual variability. Quart. J. Roy. Meteor. Soc., 133, 1143-1157.

Ueda, H., A. Iwai, K. Kuwako, and M. E. Hori, 2006: Impact of anthropogenic forcing on the Asian summer monsoon as simulated by eight GCMs. Geophys. Res. Lett., 33, L06703, doi:10.1029/ 2005 GL025336.

Wang, B., R. Wu, and K.-M. Lau, 2001: Interannual variability of the Asian summer monsoon: Contrast between the Indian and the western North Pacific-East Asian monsoons. J. Climate, 14, 4073-4090.

Webster, P. J., and S. Yang, 1992: Monsoon and ENSO: Selectively interactive system. Quart. J. Roy. Meteor. Soc., 118, 877-926. 